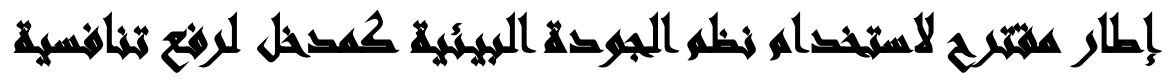

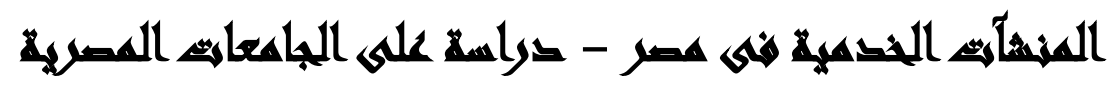 [iv]
}

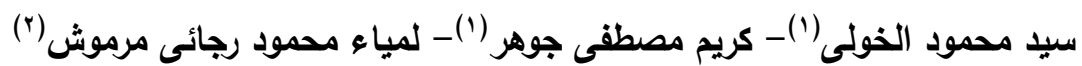

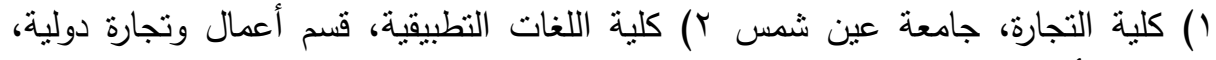
الجامعة الأهلية الفرنسية فى مصرة عين

\section{المستخلس}

يهدف البحث إلى إعداد إطار لاستخدام نظم الجودة البيئية كمدخل لرفع تتافسية

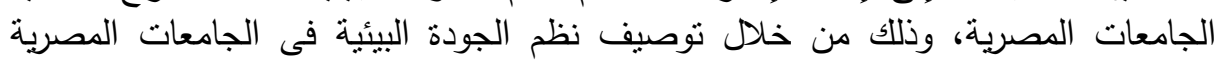

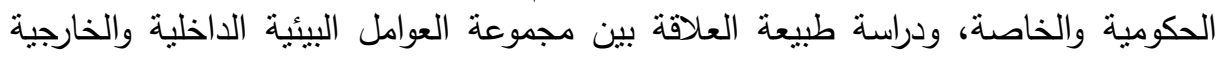

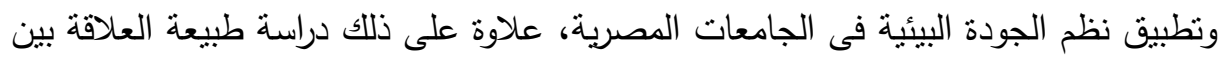

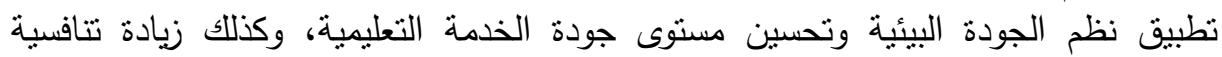
الجامعات المصرية.

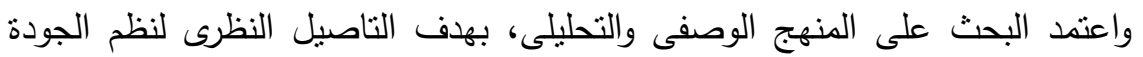

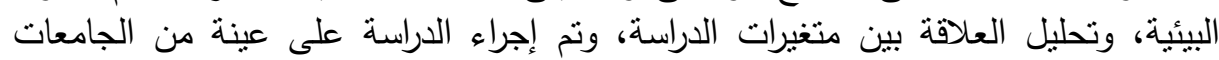

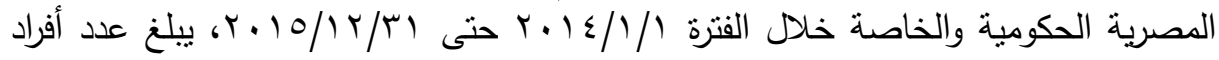

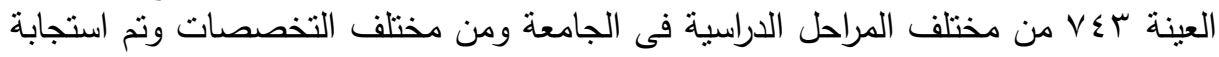

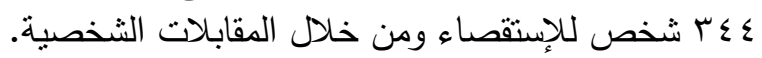

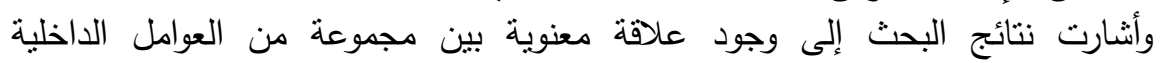

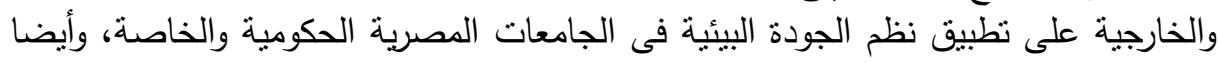

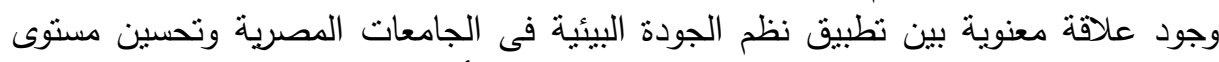

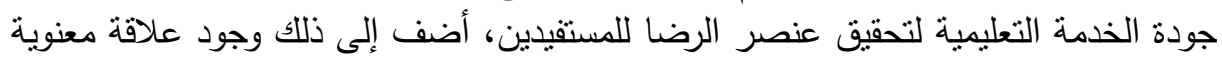

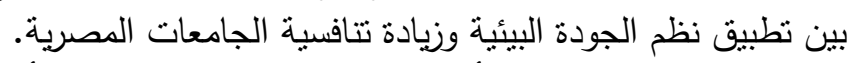

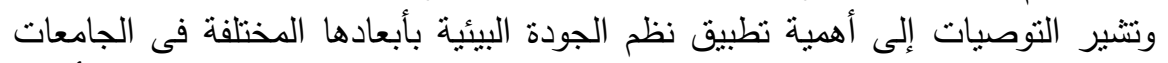

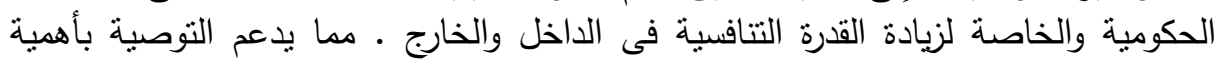

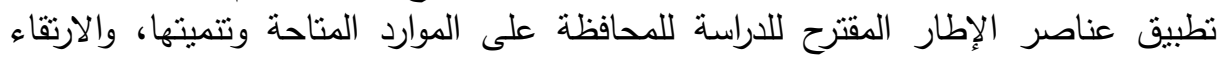

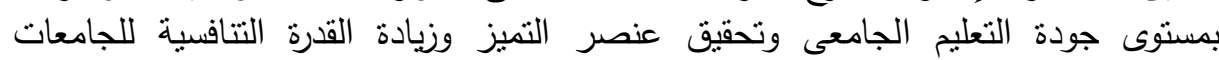




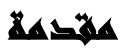

حققت الجامعات المصرية خلال القرن الحالى نتوعاً كبيراً فى التعليم العالى بما ينتاسب

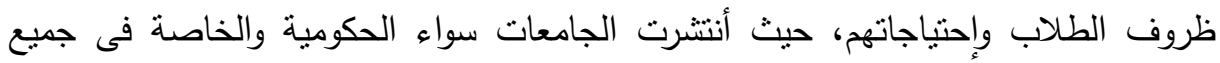
محافظات الجمهورية، وظهرت التخصصات الدقيقة بالكليات بما يواكب متطلبات تكنولوجيا العصر الحديث. وتسعى جمهورية مصر العربية إلى الإرتقاء بالمستوى التعليمى بصفة عامة بهابة بهابة

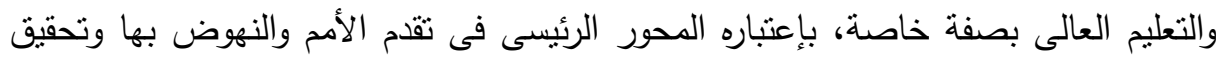

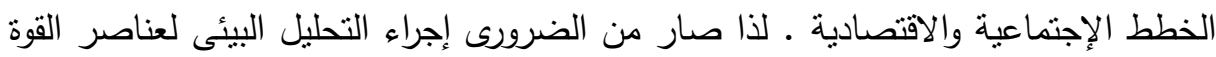

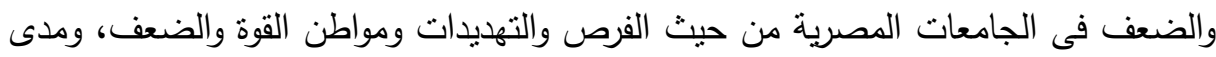
توافق نتائج التحليل مع عناصر تحسين الأداء وتحقيق التوافق البيئى ومنطلبات نظم الجودة البيئية والتى تساعد بدورها فى تعزيز القوة التتافسية للجامعات المصرية.

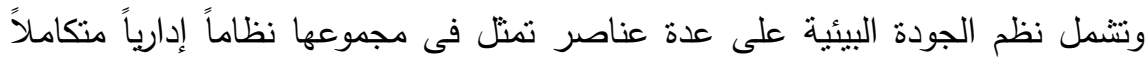
يهدف إلى تحسين الصورة الذهنية للمنشأة لدى أصحاب المصالح : Stakeholders مما بزيد من قدرتها على التميز ورفع القدرة التتافسية أمام المنشآت الأخرى المنافسة (Hillary,2000).

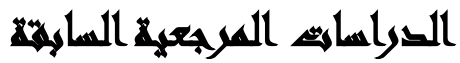

توجد بعض الدراسات التى تتاولت موضوعات مرتبطة بموضوع البحث، من أهمها :

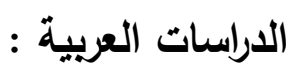

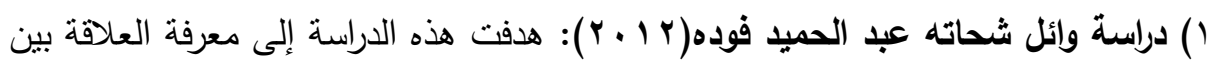

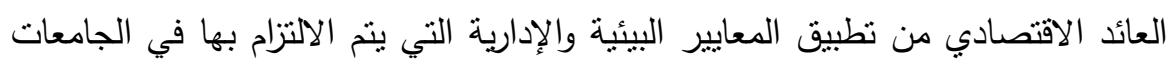

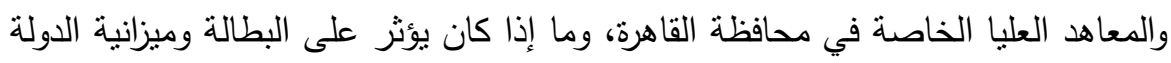
وفرص التعليم للطلبة. 
وتوصلت الدراسة إلى إمكانية تصنيف العمليات داخل الجامعات الخاصة إلى عمليات رئيسية وعمليات فرعية هادفة إلى التأكد من طبيعة العمليات بغرض تحديد عناصر الجودة البيئية والإدارية، بالإضافة إلى ذللك، وجود علاقة واضحة بينه بين نطبيق المعايير البيئية والإدارية والتى تلنزم بها الجامعات والمعاهد العليا وتحقيق عائد إقتصادى ملائم.

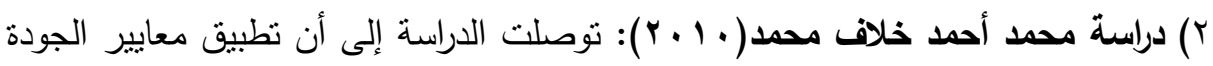
البيئية - على عكس ما يظنه البعض - لا تزيد من التكاليف، بل تؤدي لحماية البيئة وتساعد المنشأة على إنتاج نظيف وصديق للبيئة يؤدي لرضاء العيل وزيادة المبيعات لئل والتزام المنشأة بالتشريعات مما يحميها من الغرامات والعقوبات. كل تلك الأمور ساعدت على تحسين صورة المنشأة وقدرتها على تسويق منتجها وبالتالي زيادة ربحيتها وقد أوصى الباحث بضرورة وضع استراتيجية تسويقية واضحة نراعي المعايير

r) دراسة أحمد عادل محمد يوسف سلام(• ( + ): هدفت هذه الدراسة إلى وضع نموذج

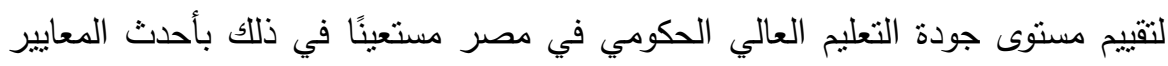
العالمية، ومن ثم تصحيح ما يوجد به من قصور، وقد توصل الباحث إلى وجود على علاقة

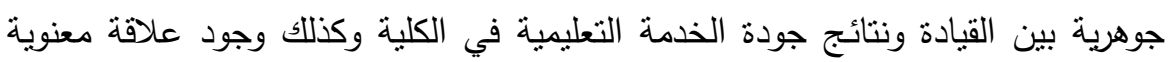
بين جودة التخطيط الاستراتيجي للكلية وجودة الخدمة التعليمية .

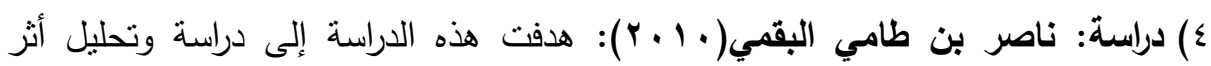
الثقويم الذاتي على تحسين الجودة الثاملة للتعليم العالي على جامعة الملك سعود بالمملكة العربية السعودية، وتبين من خلال هذه الدراسة والفروض الخاصة بها أهمية تطبيق نظم التقويم الذاتي في تحسين جودة التعليم العالي خاصة إذا ما تم من وجهة نظر الأطراف المعنية، أي أعضاء هيئة التدريس والطلاب والعاملين وتقويم مختلف جوانب العملية التعليمبة مما بيساعد على نطويرها وتحسين الأداء وتحقيق الجودة. 
0) دراسة محمد درويش، عبادة سرحان، أحمد بيومي(9 . . †) : تتاولت هذه الدراسة تحليل وتدقيق نظم المعلومات البيئية لتقنيات العمل الصحفي بما فيه من النشاط الأساسي وهوانه تقنيات الطباعة التكنولوجية الحديثة وتوصلت هذه الدراسة إلى أن نطبيق نظم المعلومات البيئية في المؤسسات الصحفية القومية المصرية يسهم ولاشك في تحسين الأداء وتجويد العمل بما يحقق جودة عامة في النواحي الاقتصادية والبيئية نتيجة كفاءة جميع العمليات والآليات المختارة التي ساهمت في التحسين للأداء الاقتصادي والبيئي للعمليات.

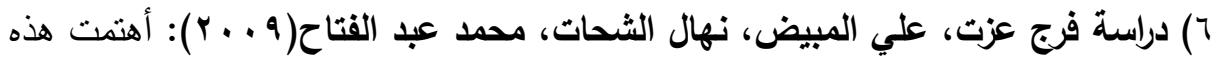
الدراسة بتقديم نموذج يهدف لتحسين وتطوير الأداء للقوى البشرية العاملة في مجال الفنادق العائمة في إطار من التوافق مع المنظومة البيئية لتخفيض الخلل الحادث في

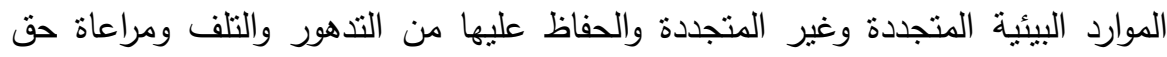
الأجيال القادمة في الاستمتاع بموارد نقية بصفة دائمة .

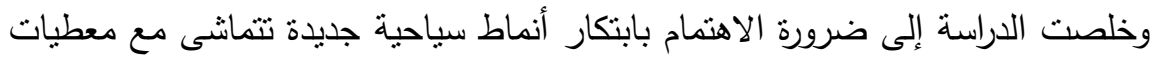

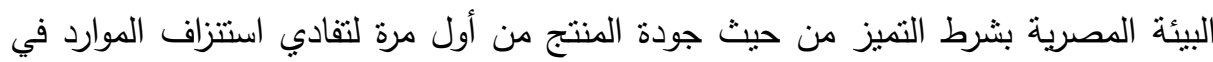
حالة إجراء تجارب منسرعة غير مدروسة .

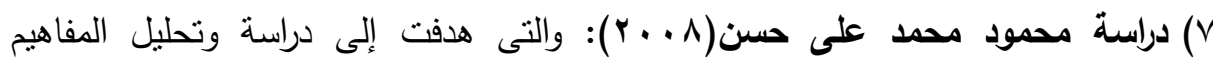
والمبادئ الأساسية لنظم تقييم الأداء فى ضوء مبادئ ولئ و معايير الجودة الثاملة. ومن أهم

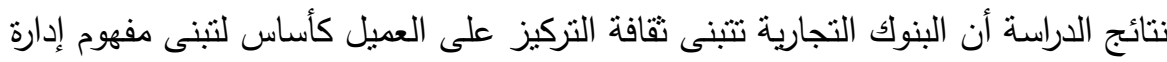
العلاقات العامة. وخلصت الدراسة إلى أهمية التحسين المستمر للجودة لضمان نجاح عملية تقييم الأداء

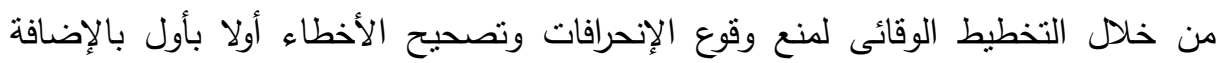
للتحكم فى العمليات.

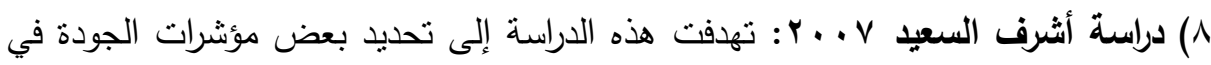
التعليم الجامعي، والتعرف على واقع الجودة في الكليات من خلال تطبيق بعض مؤشرات

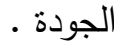


وتوصلت الدراسة إلى أن مستوى أداء كليات التربية منخفض من وجهة نظر الطلاب، وطلاب الدراسات العليا وأعضاء هيئة التدريس، كما أوصت بالعمل على تطوير التعليم

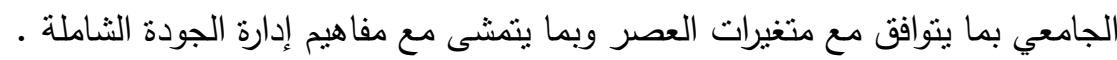

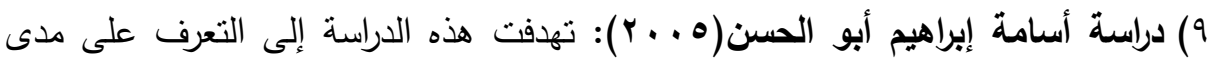

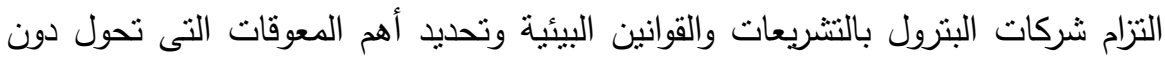
تطبيق نظام الإدارة البيئية. وخلصت الدراسة إلى ضرورة قيام شركات البترول بتطبيق نظام الإدارة البيئية والحصول

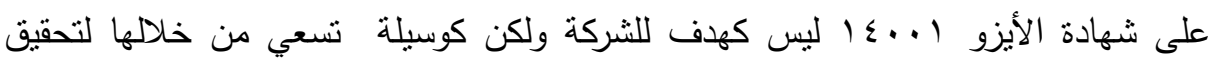
أهداف عامة للمجتمع والمساهمين والعاملين.

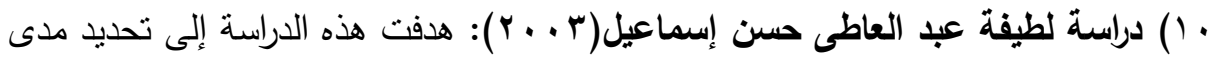
تأثثر إدارة الجودة البيئية على البيئة الداخلية والخارجية للمنظمة الخدمية فى ظل نطئل نطبيق نظام إدارة الجودة البيئية والذى ينعكس على النشاط الدقدم إلى الطلاب المقيمين بالددينة

وقد أظهرت نتائج الدراسة أن الأخذ بأساليب الإدارة الحديثة ومنها نظام إدارة الجودة

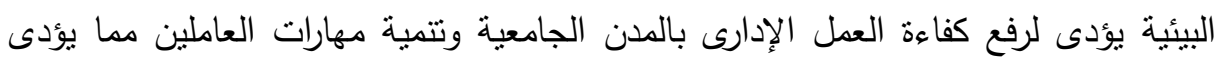

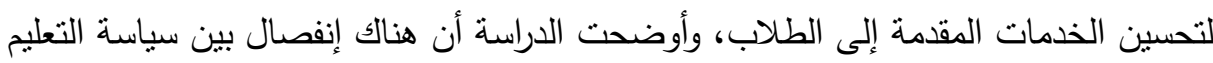

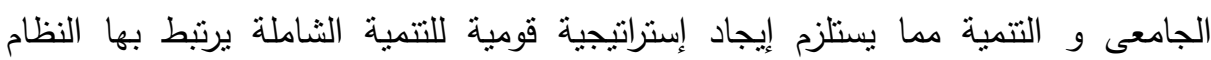
الجامعى فى جميع قطاعاته.

(1) دراسة صلاح حسن على سالم( ( . . Y): هدفت هذا البحث إلى ضرورة التوعية بمدخل

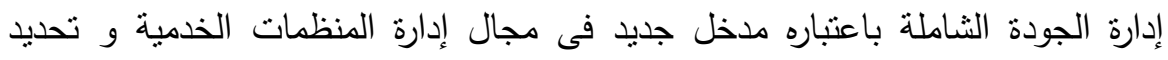

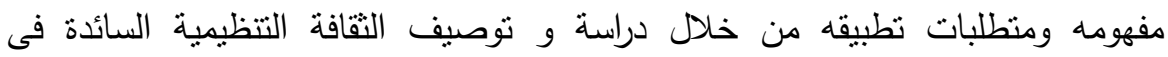
الجامعات الحكومية ومدى نوافقها مع منطلبات تطبيق إدارة الجودة الثاملة، وأهم نتائج هذا البحث تتلخص فى عدم ملاعمة الثقافة التنظيمية السائدة فى الجامعات الحكومية فى لهى مصر مع منطلبات الجودة الثاملة.

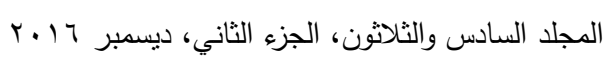




\section{2- Junquera, Beatriz; Del Brío, Jesús A and Fernández, Esteban} (2012):

هدفت هذه الدراسة إلى دراسة مدى مساهمة العملاء فى تحسين الأداء البيئي للمنشأة وذللك بالتطبيق على عدد من الثركات الأسبانية التى تطبق مفهوم الإدارة البيئية وكانت أهم التهاء

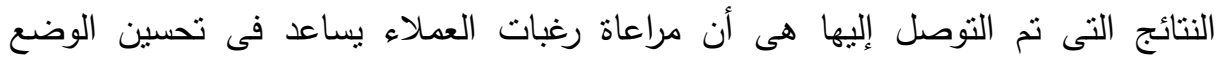
التتافسي للمنشأة وفى تيسير غزو الأسواق الأجنبية وكذللك فى تحسين الأداء النتظيمى للمنشأة. وركزت التوصيات على ضرورة دراسة أفضل أسلوب للتعاون بين المنشأة والعملاء

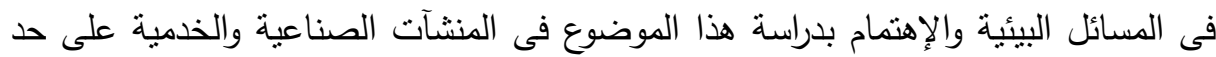
سواء مع ضرورة وضع نموذج واضح للتعاون بين إدارة المنشأة وعملائها لتعزيز الأداء البيئي. 13- Nikolaou, I.E.; Evangelinos, K.I. (2010):

هدفت البحث إلى دراسة وتحليل التحديات التى تواجهها شركات التعدين فى اليونان التى تطبق نظم الإدارة البيئية. وتمثلت نتائج الدراسة فى ضرورة توفير نظم مالية واضحة لتيسير

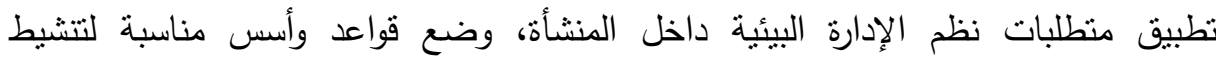

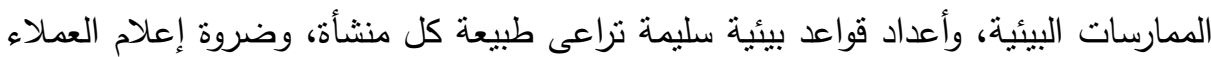

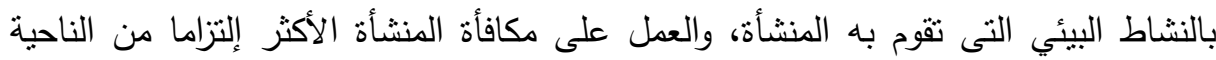
البيئية و كذللك إقامة ورش عمل دورية لتوعية وتدريب العاملين والمديرين بيئيا.

\section{4- Marmouche, Lamia (2009):}

هدفت هذه الدراسة إلى التعرف على الدوافع التي تشجع الثركات الصناعية في مصر

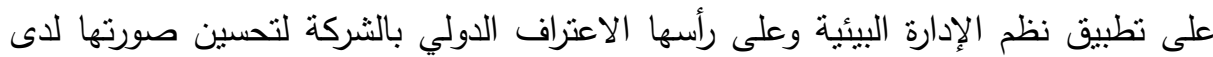

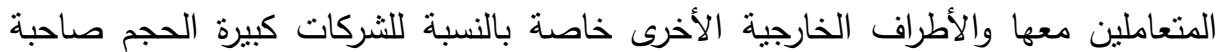

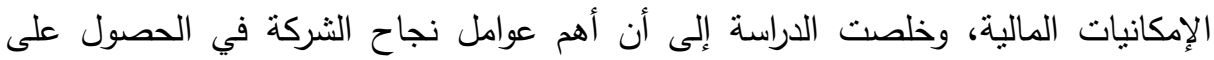
شهادة الأيزو ال .ـعا هو عنصر الخبرة في مجال الإدارة البيئية وافتتاع الإدارة والعاملين

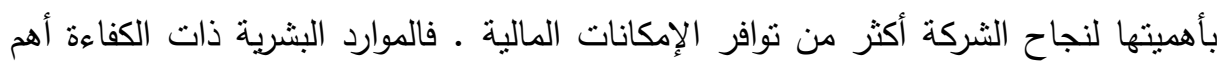

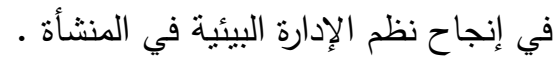


15- Mijanovic, K. and Kopac, J. (2005 :

هدفت الدراسة إلى تحليل أهم المشكلات المتعلقة بتطبيق نظم الإدارة البيئية فى الدول

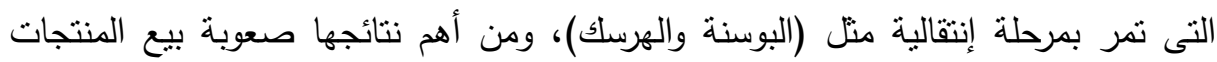

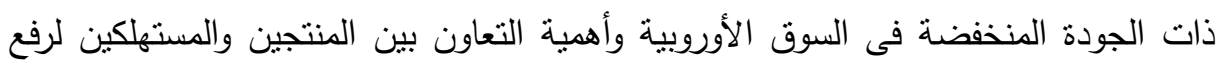
جودة المنتج. أما أهم التوصيات فهى ضرورة الإهنمام برفع درجة التعاون بين المنشأة التهات والموردين لتحسين جودة المنتج و الخدمة المقدمة للعميل.

\section{6- Sahmey, Sangeta \& Anwet (2004):}

استهدفت الدراسة توضيح مفاهيم إدارة الجودة الثاملة في ضوء احتياجات التعليم العالي

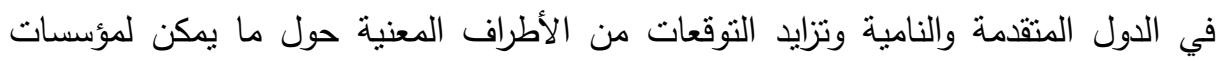

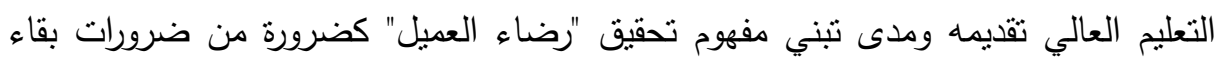

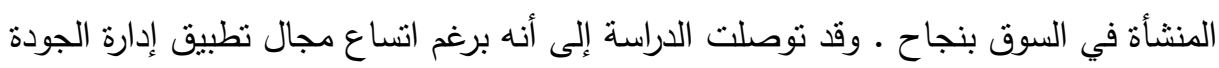

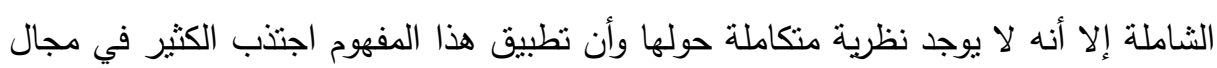

17- Sirounci, Mete B. (2004):

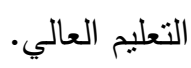

استهدفت هذه الدراسة اقتراح أسلوب للتغلب على العقبات في استخدام إدارة الجودة

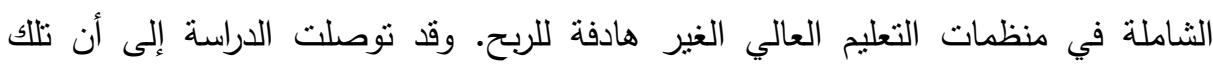

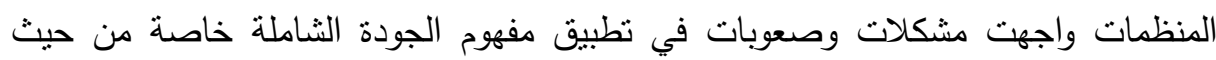
ارتفاع تكلفة خدمة التعليم العالي، مما قد يؤثر على كفاءة الخدمة التعليمية.

\section{8- Viebahn, Peter (2001):}

هدفت البحث إلى دراسة أثز تطبيق نظم الإدارة البيئية فى الجامعات على ترشيد

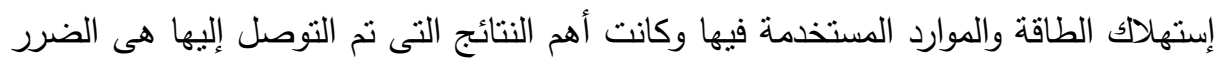

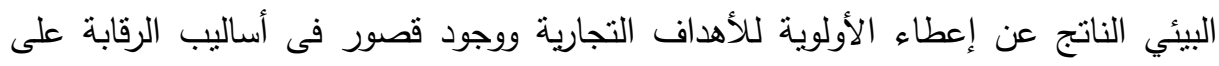

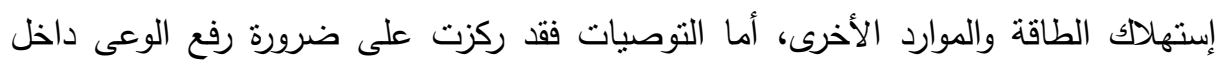

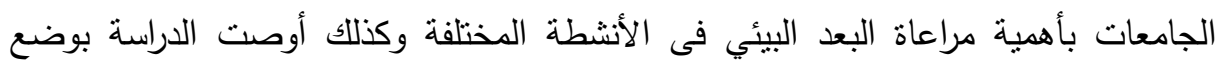

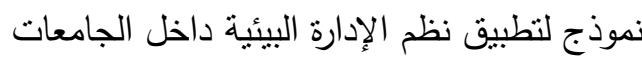

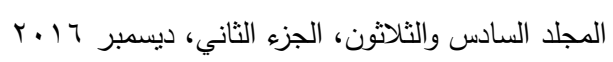


وعلى الرغم من الإسهامات التى أضافتها الدراسات السابقة فى مجال إدارة الأعمال

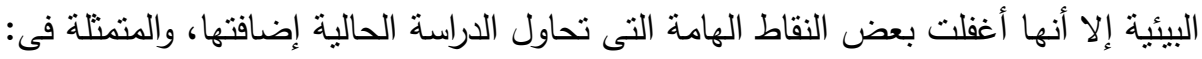
- - الدور الذى تلعبه نظم الجودة البيئية فى رفع التنافسية بين المنظمات وخاصة الخدمية. - العوامل الأكثر تأثيراً على نطبيق نظم الجودة البيئية فى المنظمات الخدمية. - مدى وجود علاقة بين تطبيق نظم الجودة البيئية وتحسين مستوى جودة الخدمات المقدمة للعملاء.

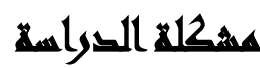

تعتبر نظم الجودة البيئية ثقافة منطورة تتفق مع منطلبات العصر الحديث والمنتملة فى

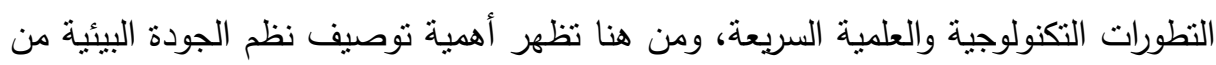

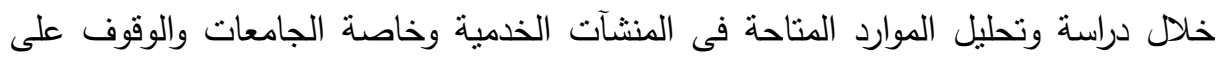

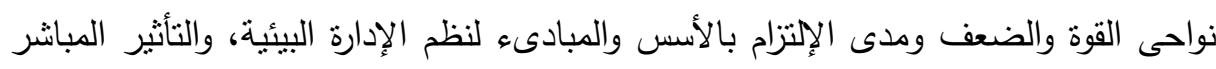
على الوضع التتافسى والعلاقات بالمنظمات الخارجية (ضياء الدين زاهر ،0.0. . ب).

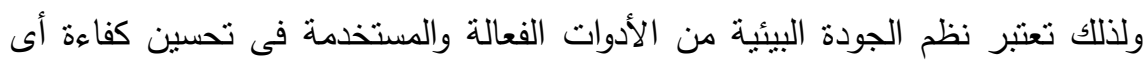

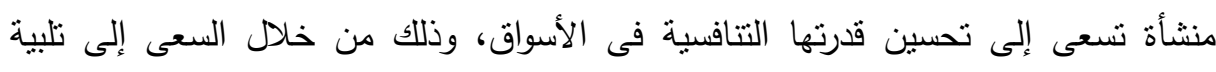
إحتياجات ورغبات العملاء فى إطار نطبيق معايير وإشتراطات الجودة فى جميع مرنى مراحل العمليات والإنتاج.) (Feigenbaum, A. V., 1991) وفى إطار سعى الدولة إلى تحقيق التنمية الإقتصادية والإجتماعية، برز الإتجاه إلى

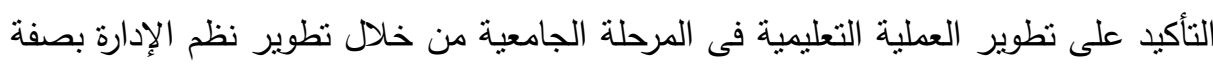

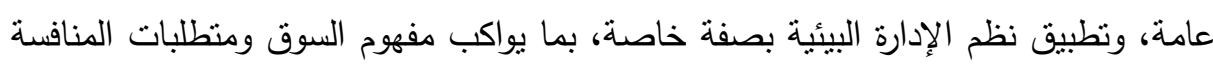

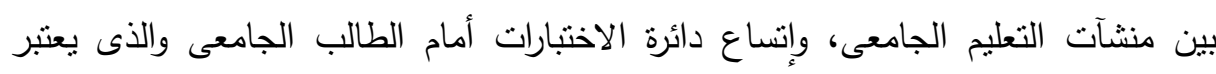
العميل الأساسى لتلك المنشآت الخدمية. 


\section{من خلال عرض الدراسات السابقة يتضح أنها تدور حول النقاط التالية :} • • توصيف خصائص الجودة للخدمات المقدمة فى المنشآت الخدمية. • معرفة العلاقة بين العائد الاقتصادى وتطبيق المعايير البيئية بالجامعات والمعاهد العليا المصرية، والحصول على شهادة الإيزو ال ... ا لجودة الإدارة البيئية.

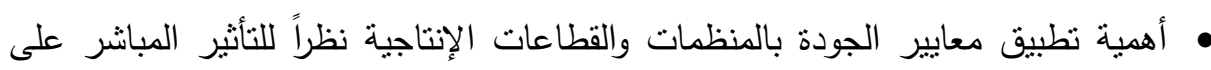
نماذج نطبيق الإستراتيجيات التسويقية وتبنى مفهوم التسويق الأخصر وإرضاء العميل.

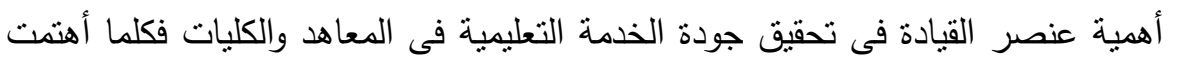

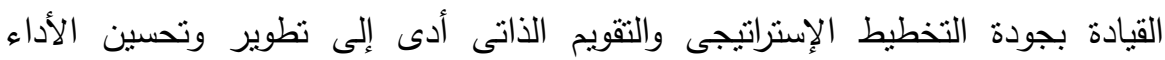
والارتفاع بجودة الخدمة التعليمية. هور عنصر الاتصال مع الجمهور الخارجى وتزويده بالبيانات والمعلومات المتاحة (دور العلاقات العامة) فى تتمية الأداء البيئى فى المنظمات الإنتاجية.

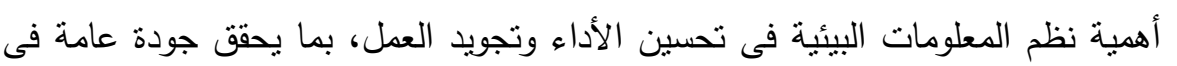
جميع المجالات بالمنشأة، والمساهمة فى تحسين الأداء الاقتصادى والبيئى.

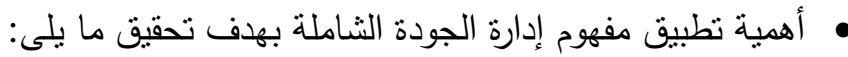
- تلبية رغبات الجماهير الداخلية (الموظفين والعمال) والخارجية (العميل وأصحاب (المصالح) - - تصحيح الأخطاء والتحكم فى العمليات ومؤشرات الجودة والمعايير البيئية. - - تحسين مستوى جودة الخدمة التعليمية فى الجامعات المصرية. - معرفة المشاكل والتحديات التى تواجه المسئولين عن تطبيق مفاهيم إدارة الجودة الثشاملة. • معرفة أثز تطبيق الإدارة البيئية على تحقيق أهداف أصحاب المصالح والمهتمين بأداء المنظمة، وأهمية الأخذ بأساليب الإدارة الحديثة ومنها نظام إدارة الجودة البيئية لرفع كفاءة العمل الإدارى وتتمية مهارات العاملين، مما يؤدى إلى تحسين جودة الخدمات المقدمة 
• التعرف على منطلبات تطبيق نظم جودة الإدارة البيئية داخل المنشآت، والقواعد والأسس المناسبة لتنشيط الممارسات البيئية.

وعلى الرغم من الإسهامات التى أضافتها الاراسات السابقة فى مجال إدارة الأعمال البيئية إلا أنها أغقلت بعض النقاط الهامة التى تحاول الدارسة الحالية إضافتها، والمتمثئة فى:

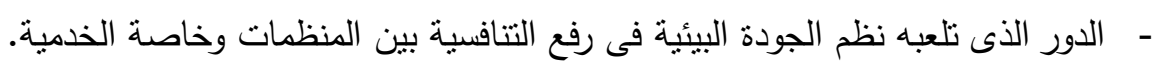
- العوامل الأكثر تأثيراً على نطبيق نظم الجودة البيئية فى المنظمات الخدمية. - مدى وجود علاقة بين نطبيق نظم الجودة البيئية وتحسين مستوى جودة الخدمات المقدمة ل اللعملاء. وبناءً على ما سبق، فإن الدراسة الحالية تطرح التساؤلات التالية :

\section{أسئلة الصوراسة}

• إلى أى مدى تساعد نظم الجودة البيئية فى رفع تتافسية الجامعات المصرية ؟

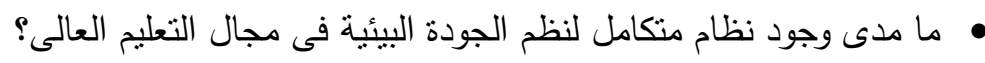

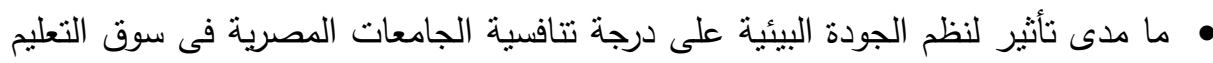

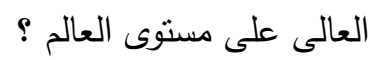
• • ما مدى إلتزام الجامعات المصرية بالمعايير والثروط البيئية؟ ؟

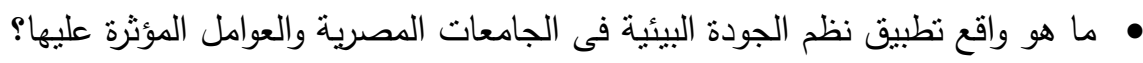
• هل يوجد إختلافات بين الجامعات الحكومية والجامعات الخاصة في أسلوب تصدئ تحسين مستوى الخدمة التعليمية لتحقيق عنصر الرضا للمستفيدين منها؟ 


\section{أهمية السوراسة}

يمكن توضيح الأهمية العلمية والعملية للاراسة كما يلى:

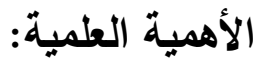

- محاولة تأصيل الأسلوب العلىى فى إدارة المنشآت الخدمية، من خلال نطبيق نظم الجودة البيئية، للإتفادة فى تطوير وتحسين مستويات الجودة والإنتاجية داخل المنشآت الخدمية فى لئي

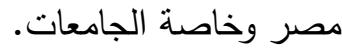

- - يمثل تطبيق نظم الجودة البيئية فى الجامعات المصرية أحد الدداخل الإدارية الحديثة فى توفير بيئة مناسبة لممارسة الأساليب والإجراءات المرتبطة بتحسين الأداء ودمج البعد

$$
\text { البيئى فى نسيج الجامعات المصرية. }
$$

- - إلقاء الضوء على أهية تطبيق لعناصر نظم الجودة البيئية بهدف رفع نتافية الجامعات

$$
\text { المصرية والحكومية والخاصة فى وسق التعليم الجامعى. }
$$

- - تمنل الدراسة نقطة إنطلاق وتحول نحو تطبيق نظم الجودة البيئية وعناصرها الرئيسية على

المنشآت الخدمية، بغرض زيادة درجة التفاعل بين الجامعة وبيئتها الخارجية.

- تمنل الدراسة محاولة لسد الفجوة البحثية المتعلقة بكيفية الإستفادة من نظم الجودة البيئية من خلال إعداد إطار شامل يعكس عناصرها الأساسية، ويوفر مقومات النجاح وأهداف لاف لإنال الأطراف المرتمة بأداء الجامعات.

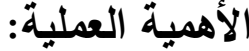

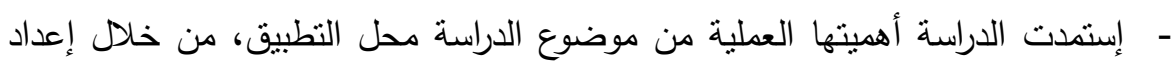
إطار لنظم الجودة البيئية يساعد فى رفع تتافسية الجامعات المصرية والارتقاء بمستوى جودة الخدمات التعليمية المقدمة، علاوة على مواكبة متطلبات سوق العمل.

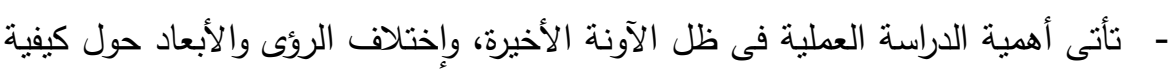
تطوير منظومة التعليم فى مصر وخاصة التعليم الجامعى بأعتبارها القاطرة الأساسية

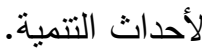

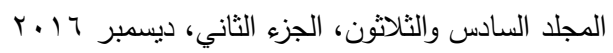


- تقديم مجموعة من التوصيات للمسئولين والجهات المهتمة بالتعليم الجامعى فى مصر،

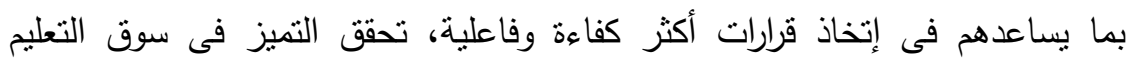

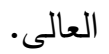

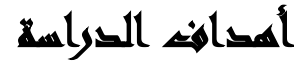

يكمن الهدف الرئيسى للاراسة فى إعداد إطار لاستخدام نظم الجودة البيئية كمدل

رئيسى لرفع تتافسية الجامعات المصرية " وينبثق من الهدف الرئيسى عدة أهداف فرعية: - توصيف نظم الجودة البيئية فى الجامعات المصرية الحكومية والجامعات الخاصة لمعرفة مدى وجود إختلافات بينهما فى تحسين مستوى جودة الخدمة التعليمية، وتحقيق عنصر الرضا للمستقيدين.

- - دراسة طبيعة العلاقة بين مجموعة العوامل البيئية الداخلية والخارجية على استخدام نظم الجودة البيئية - ومن خلال دراسة وتحليل البيئة الداخلية والخارجية - وبين نطبيق نظم الجودة البيئية فى الجامعات المصرية. - - دراسة طبيعة العلاقة بين نطبيق نظم الجودة البيئية فى الجامعات المصرية وتحسين مستوى جودة الخدمة النعليمية. - دراسة طبيعة العلاقة بين استخدام نظم الجودة البيئية وزيادة تنافسية الجامعات المصرية.

\section{هروخ التواسما}

فى ضوء مشكلة الاراسة وأهدافها، يحاول الباحثون إثبات مدى صحة الفروض التالية: الفرض الأول: " لا توجد فروق جوهرية لإستخدام نظم الجودة البيئية لرفع التتافسية بين

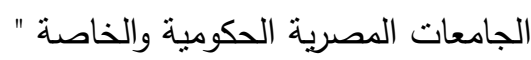
الفرض الثاني: " لا يوجد علاقة معنوية ذات دلالة إحصائية بين مجموعة العوامل المؤثرة

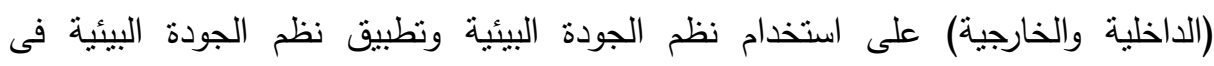
الجامعات المصرية" 
الفرض الثالث: " لا نوجد علاقة معنوية ذات دلالة إحصائية بين تطبيق نظم الجودة البيئية

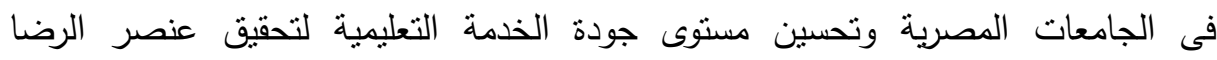

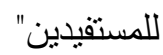

الفرض الرابع: " لا توجد علاقة معنوية ذات دلالة إحصائية بين إستخدام نظم الجودة البيئية وزيادة تنافسية الجامعات المصرية " لورجية

\section{هورو السواسما}

تتمثل حدود الدراسة فى المحدات التالية : • العناصر المرتبطة باستخدام نظم الجودة البيئية ومدى تأثثرها على رفع كفاءة القدرة التنافسية للمنشآت الخدمية وتتمنل تلك العناصر فئى العوامل المؤثرة (الداخلية / الخارجية) على تطبيق نظم الجودة البيئية ومنها مدى توافر البيانات والمعلومات اللازمة لإدارة الكلية، أثز قنوات الإتصال بين العاملين بالكلية لتبادل الآراء، وجود خطة فعالة لنطبيق نظم لنابل

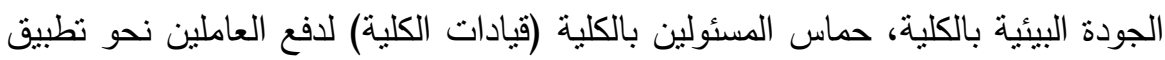
نظم الجودة البيئية، إتجاهات المستقيدين بالخدمات التعليمية، أثز شبكات التواصل باتل الإجتماعي وتكنولوجيا المعلومات بشكل فعال علي تتمية رغبات المستفدين الحاليين

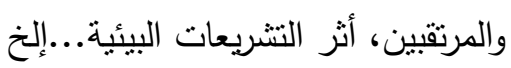
هاتباع أسلوب العينة وليس الحصر الثامل فى تتفيذ الدراسة الميدانية، نظراً لزيادة مفردات الدراسة والبحث ومحدودية الوقت والجهد. • تقتصر الدراسة على عينة من الجامعات الحكومية والخاصة. - - الجامعات الحكومية : جامعة القاهرة، جامعة عين شمس. - - الجامعات الخاصة : الجامعة الفرنسية، الجامعة الحديثة. • اقتصرت على الأطراف المهتمة بإدارة الجودة والنظم البيئية فى الكليات.

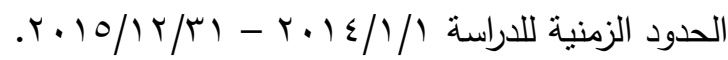




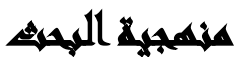

لتحقيق أهداف الدراسة والوصول إلى إعداد إطار لإستخدام نظم الجودة البيئية لرفع تتافسية الجامعات المصرية، فقد تم الاعتماد على المنهج الوصفى والتحليلى، وذلك من خلال

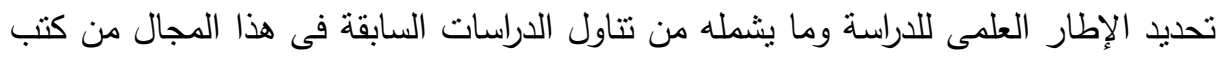
ومراجع ودوريات ودراسات علمية باللغة العربية والإنجليزية، بهذف التاصيل النظرى لنظم الجودة البيئية، علاوة على ذلك تحليل العلاقة بين العوامل الداخلية والخارجية المؤثرة على إستخدام نظم الجودة البيئية فى الجامعات المصرية، وكذلك تحليل العلاقة بين نظم الجودة البيئية وتحسين مستوى جودة الخدمة التعليمية ورفع مستوى المنافسة للجامعات المصرية.

$$
\text { وبالتالى فقد اعتمدت الدراسة على: }
$$

أ- أسلوب الاراسة النظرية: وذلك بهدف الحصول على البيانات الثانوية وتحديد المفاهيم النظرية والمصطلحات الأساسية وتأصيل الإطار العلمى للاراسة.

ب- أسلوب الاراسة الميدانية: حيث يتم إجراء الدراسة على عينة من الجامعات المصرية الحكومية والخاصة، بهدف الحصول على البيانات الأولية للاراسة.

\section{إلبراءاهت الهيه}

مجتمع الدراسة وعينة البحث: يتمثل مجتمع البحث فى الجامعات المصرية الحكومية

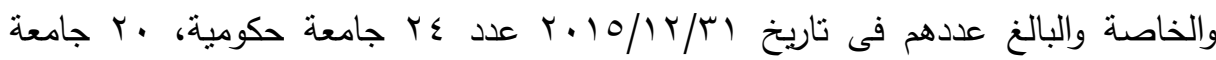
خاصة.

ونظراً لإنتشار مجتمع الدراسة فى مختلف المحافظات المصرية، فقد أختار الباحثون

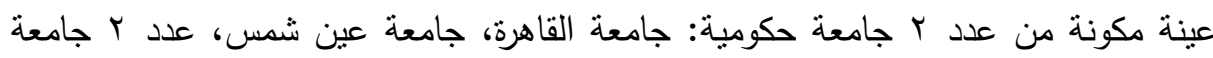

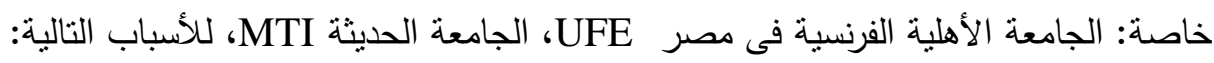
- تمنل جامعة القاهرة وعين شمس الجامعات الحكومية المعروفة بتطبيق الأساليب الإدارية والتعليمية الحديثة، وعقد الإتفاقيات وبرنوكولات التعاون والثراكة مع الجامعات الأجنبية.

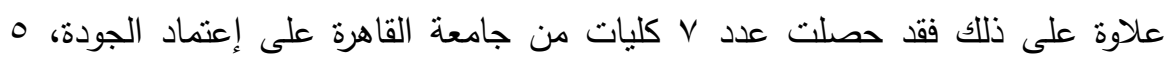


كليات من جامعة عين شمس على نفس الاعتماد، من أجمالى ب كلية حصلت على الاعتماد من الهيئة القومية لضمان جودة التعليم والاعتماد.

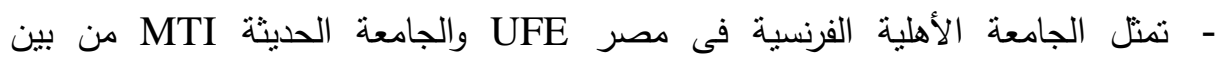
الجامعات الخاصة المتضمنة على عدة كليات، علاوة على التميز فى الأدداء الإدارى ملى هله وتطبيق تكنولوجيا وأنظمة المعلومات والاتصالات ومشاركات بيئية مختلفة. - علاوة على ذللك، فقد أختار الباحثون عينة الدراسة لسهولة جمع البيانات وإجراء المقابلات

$$
\text { الثخصية مع مفردات العينة. }
$$

وقامت الباحثة بأختيار عدد ه كليات من كل جامعة حكومية، وعدد ب كليات من كل جامعة

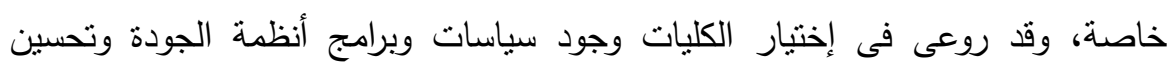
الخدمة التعليمية وكذلك فى الإدارة البيئية. وقد تضمنت مفردات الدراسة (المبحوثين) بالكليات ما يلى : - - مكيل الكلية لشئون البيئة. - - م العاملين بوحدات إدارة الجودة. - - عينة من هيئة التدريس.

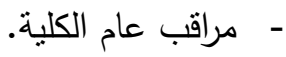

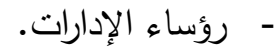

وقد بلغ عدد مفردات الدراسة من الجامعات الحكومية . . مفرده ومن الجامعات

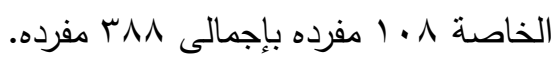
أدوات الاراسة: وقام الباحثون بالاعتماد على قائمة إستبيان لجمع البيانات المطلوبة، كأداة للاراسة الميدانية وجمع البيانات. وتم مراجعة القائمة قبل إستخدامها مع بعض السادة أساتذة

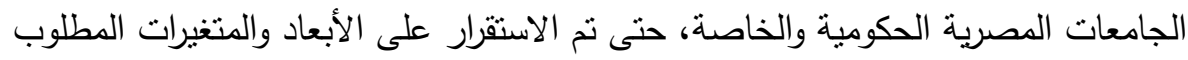
قياسها. وتمثلت تلك الأبعاد فى الآتى: 
البعد الأول: العوامل المؤثرة على إستخدام نظم الجودة البيئية (البيئة الداخلية / البيئة

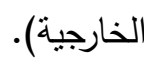

البعد الثانى: أهمية تطبيق نظم الجودة البيئية. البعد الثالث: تحسين مستوى جودة الخدمة التعليمية.

البعد الرابع: زيادة نتافسية الجامعات المصرية.

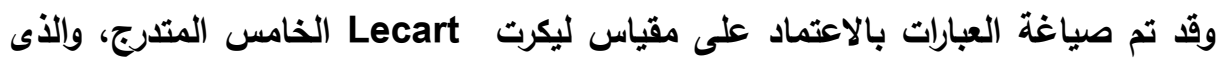
يتراوح بين إلى ه ه هما يلى:

\begin{tabular}{|c|c|c|c|c|c|}
\hline أرفض تماما & آرضض & لا آدرى & $\begin{array}{l}\text { أوافْق } \\
\text { (؛) }\end{array}$ & أوافق بشدة & العبارات \\
\hline
\end{tabular}

وذلك بهدف الحصول على المتوسط المرجح بالأوزان للعبارات وأبعاد الدراسة، ولاستخدام

الأساليب الإحصائية والتى يتم الاعتماد عليها فى تحليل بيانات الدراسة الميدانية.

صدق الأداه: وقد قامت الباحثة بعرض أداة القياس على مجموعة من الخبراء والمتخصصين للتحقق من إنتماء الأسئلة المذكورة فى قائمة الإستقصاء إلى المحور التى

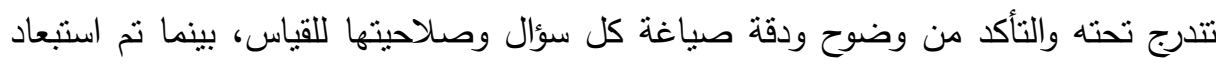
الفقرات التى لا تخضع لهذه الثروط.

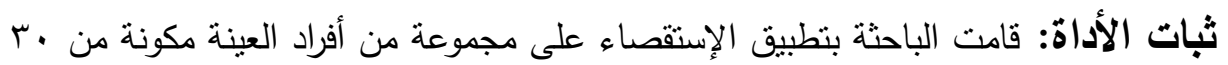

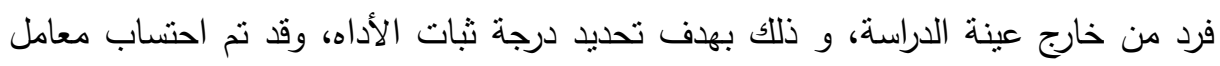
الإتساق الداخلى الذى كانت قيمته • 9. •

الأساليب الإحصائية المستخدمة لإثبات مدى صحة فروض الدراسة، ولإجراء التحليل الإحصائى على متغيرات، فقد نم الاعتماد على الحزمة الإحصائية للعلوم الاجتماعية Statistic Package For Social Sciences (SPSS) من خلال قوائم الاستبيان، وإيجاد العلاقات بين متغيرات الدراسة. 
ومن أهم الأساليب الإحصائية التى تم الاعتماد عليها عند تحليل البيانات لإجراء إختبارات

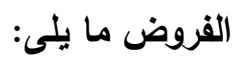
• معامل الارتباط Correlation Coefficient: لقياس درجة الارتباط بين متغيرين • وتعبر قيمة هذا المعامل-بصرف النظر عن الإثارة- عن قوة العلاقة بين المتغيرين، ويعطى برنامج SPSS مستوى الدلالة P.value. • الانحدار البسيط Simple Regression : ويعطي شكل العلاقة الخطية بين متغيرين يؤثز أحدهما وهو المتغير المستقل في الأخر وهو المتغير التابع، ويعطى برنامج SPSS

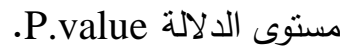

• معامل التحديد Coefficient \& Determinant: ويستخدم معامل التحديد لبيان النسبة المئوية للتفسيرات التى يستطيع تفسيرها المتغير المستقل للتغيرات التى تطرأ على ملى

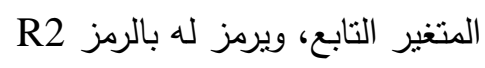
• اختبار فريدمان (الأهمية النسبية) Friedman Test : وهو اختبار لا معلمي ويستخدم لاختبار درجة التوافق أو الاختلاف بين آراء العينة ككل حول العبارات أي اختلاف

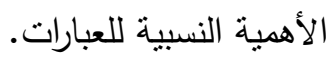
• اختبر كا' Chi Square Test : وهو اختبار يستخدم لقياس العلاقة بين المتغيرات الوصفية

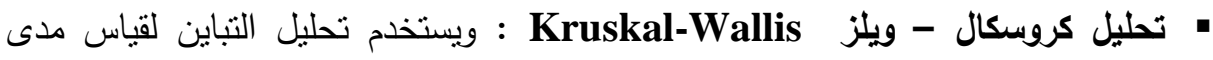
الاتفاق أو الاختلاف فى آراء مجموعات العينة المختلفة فى كل عبارة أو مشكلة من مشكلات الدراسة. • معامل ألفاكرونباخ Crombech Alpha : ويستخدم لإجراء إختبار الثبات فى عبارات

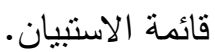
• إختبار ت Test: ويستخدم لاختبار ما إذا كان متوسط استجابة المبحوثين اكبر من أو اقل من قيمة معينة ولبيان مدى تحقق خاصية معينة من خلال الدراسة. • الوسط الحسابي: يعرف الوسط الحسابي للقيم. 
• الإنحراف المعياري: يعتبر الانحراف المعياري من أنشهر مقاييس التشتت وأكثرها استخداماً

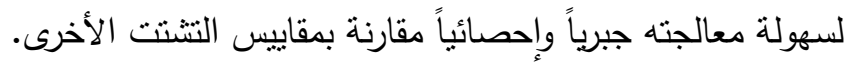

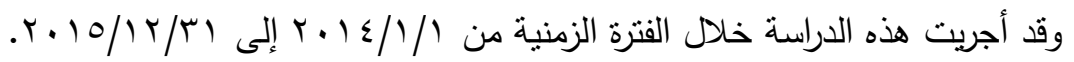

\section{المنائم}

الفرض الأول ينص الفرض الأول على: " لاتوجد إختلافات جوهرية لاستخدام نظم الجودة

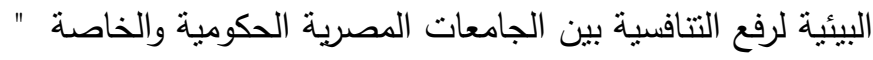

وقد قام الباحثون باستخدام اختبار كروسكال لقياس مدى الاتفاق والاختلاف بين

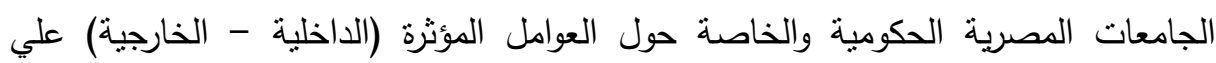

إستخدام نظم الجودة البيئية من خلال جدول (1) كما يلى:

جدول(1): تحليل التباين لقياس مدى الاتفاق والاختلاف بين الجامعات المصرية الحكومية والخاصة حول العوامل المؤثرة (الداخلية - الخارجية) علي استخدام نظم الجودة

البيئية

\begin{tabular}{|c|c|c|c|c|c|}
\hline المعنوية & ris & متوسط & العدد العد & نوع الجامعات & م \\
\hline \multirow{2}{*}{.326} & \multirow{2}{*}{.964} & 175.65 & 253 & جامعات حكومية & 1 \\
\hline & & 163.75 & 91 & جامعات خاصة & $r$ \\
\hline
\end{tabular}

يتضح من الجدول السابق:

أن مستوى المعنوية أكبر من 5\% وهذا يعنى أنه يوجد إتفاق بين الجامعات المصرية

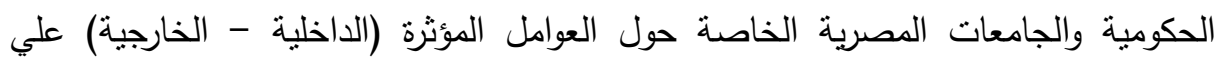

إستخدام نظم الجودة البيئية .

قام الباحثون باستخدام اختبار كروسكال لقياس مدى الاتفاق والاختلاف بين الجامعات

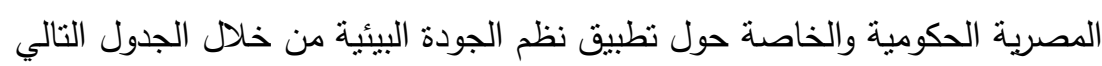


جدول(ץ): تحليل التباين لقياس مدى الاتفاق والاختلاف بين الجامعات المصرية الحكومية والخاصة حول تطبيق نظم الجودة البيئية.

\begin{tabular}{|c|c|c|c|c|c|}
\hline المعنوية & كاץ & متوبط الرتب & العدد & نوع الجامعات & م \\
\hline \multirow{2}{*}{.000} & \multirow{2}{*}{12.279} & 161.27 & 253 & جامعات حكومية & 1 \\
\hline & & 203.72 & 91 & جامعات خاصةة & r \\
\hline
\end{tabular}

يتضح من الجدول السابق: أن مستوى المعنوية أقل من 5\% وهذا يعنى أنه يوجد إختلاف بين

الجامعات المصرية الحكومية والجامعات المصرية الخاصة حول تطبيق نظم الجودة البيئية. قامت الباحثة باستخدام اختبار كروسكال لقياس مدى الاتفاق والاختلاف بين الجامعات

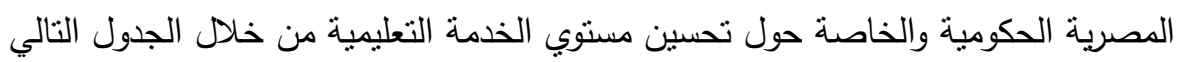
جدول(ץ): تحليل التباين لقياس مدى الاتفاق والاختلاف بين الجامعات المصرية الحكومية والخاصةحول تحسين مستوي الخدمة التعليمية

\begin{tabular}{|c|c|c|c|c|c|}
\hline المعنوية & sir & متوبط & العدد العد & نوع الجامعات & م \\
\hline \multirow{2}{*}{.000} & \multirow{2}{*}{15.180} & 160.06 & 253 & جامعات حكومية & 7 \\
\hline & & 207.08 & 91 & جامعات خاصة & $r$ \\
\hline
\end{tabular}

يتضح من الجدول السابق: أن مستوى المعنوية أقل من 5\% وهذا يعنى أنه يوجد إختلاف بين الجامعات المصرية الحكومية والجامعات المصرية الخاصة حول تحسين مستوي الخدمة التعليمية.

قامت الباحثة باستخدام اختبار كروسكال لقياس مدى الاتفاق والاختلاف بين الجامعات

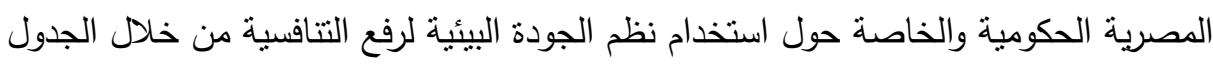
التالي جدول(§): تحليل التباين لقياس مدى الاتفاق والاختلاف بين الجامعات المصرية الحكومية والخاصةحول استخدام نظم الجودة البيئية لرفع التتافسية.

\begin{tabular}{|c|c|c|c|c|c|}
\hline المعنوية & كا' & متوبط & العدد & نوع الجامعات & p \\
\hline \multirow{2}{*}{.000} & \multirow{2}{*}{6.450} & 164.37 & 253 & جامعات حكومية & 7 \\
\hline & & 195.11 & 91 & جامعات خاصة & 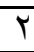 \\
\hline
\end{tabular}


يتضح من الجدول السابق: أن مستوى المعنوية أقل من 5\% وهذا يعنى أنه يوجد إختلاف بين الجامعات المصرية الحكومية والجامعات المصرية الخاصة حول استخدام نظم الجودة البيئية لرفع التتافسية.

الفرض الثاني ينص الفرض الثاني على : " لاتوجد علاقة معنوية ذات دلالة إحصائية بين مجموعة العوامل المؤثرة (الداخلية - الخارجية) علي إستخدام نظم الجودة البيئية وتطبيق نظم الجودة البيئية في الجامعات المصرية" أولا: قياس مدى قوة العلاقة بين المتغير التابع والمتغير المستقل (قياس معامل الارتباط)

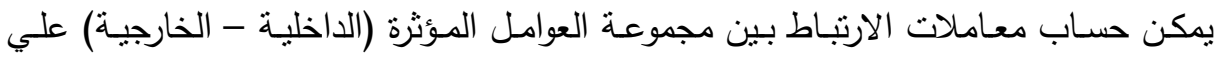
إستخدام نظم الجودة البيئية (كمتغيرات مستقلة ) وبين تطييق نظم الجودة البيئية (كمتغير تابع) كما يتضح من الجدول التالى:-

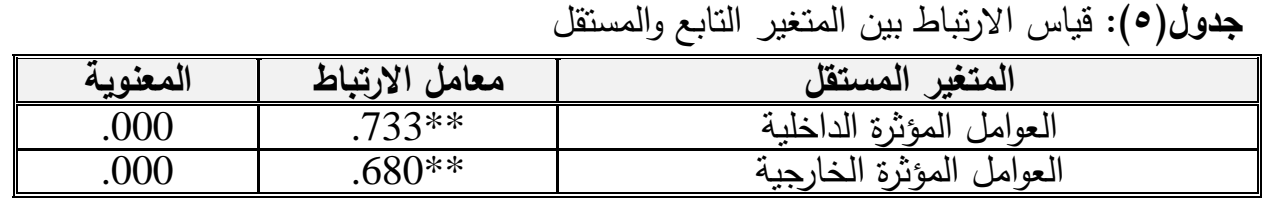

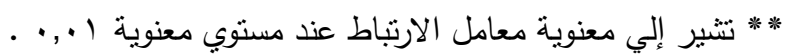

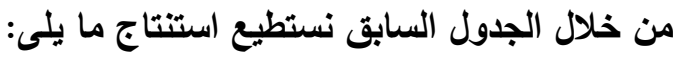

- وجود علاقة ارتباط بين عبارات المتغيرات المستقلة مجموعة العوامل المؤثرة (الداخلية الخارجية) علي إستخدام نظم الجودة البيئية وعبارات المتغير التابع (تطبيق نظم الجودة البيئية) حيث أن معاملات الإرتباط =(680. - 733.) كما أن مستوى المعنوية (الدلالة) أقل مـن 1\% وهذا أيضـاً يـلـل على وجـود علاقـة ارتبـاط بين المتغيـر التـابع والمتغير

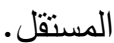
- وجود علاقة ارتباط طردية (إيجابية) بين عبارات المتغيرات المستقلة مجموعة العوامل

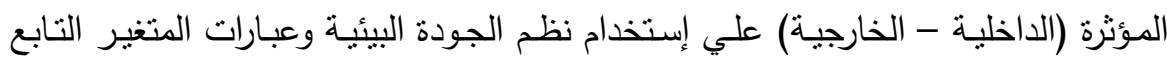
(تطبيق نظم الجودة البيئية) حيث إثـارة معامل الارتباط موجبة، وهذا يعنى وجود علاقة إسبة 
إيجابية، فكلما كان هنالك اهتمـام بمجموعـة العوامل المؤثرة (الداخليـة - الخارجيـة) علي إستخدام نظم الجودة البيئية أدي ذلك إلي تطبيق نظم الجودة البيئية.

ثانيا: قياس أثر كل متغير مستقل على المتغير التابع على حده ( الانحدار البسيط ) - يثير تحليل الانحدار البسيط إلى شكل العلاقة الخطية بين المتغير المستقل والمتغير التابع، ونسبة تأثنير المتغير المستقل (العوامل المؤثرة الداخلية) على المتغير التابع (تطبيق لئن

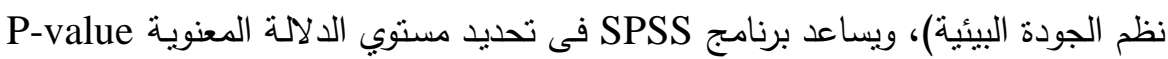
والجدول التالى يوضح تحليل الانحدار البسيط بين المتغيرالمستقل والمتغير التابع. جدول(؟): قياس الارتباط بين المتغير التابع والمستقل بيان علاقة الانحدار بين المتغير

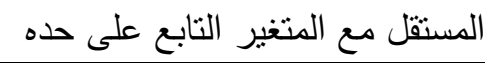

\begin{tabular}{|c|c|c|c|c|c|}
\hline التحديد (Rعل & الاحصائية & $\begin{array}{c}\mathrm{P}- \\
\text { value }\end{array}$ & قيم اختبار & القِّرة & المعالم \\
\hline \multirow{2}{*}{.537} & دالة & $\bar{~} .000$ & 15.154 & 20.349 & الجزء الثابت \\
\hline & 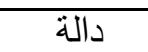 & .000 & 19.936 & .623 & العوامل المؤثرة الداخلية \\
\hline \multicolumn{6}{|c|}{ قيمة اختبار (ف) = 397.456} \\
\hline
\end{tabular}

يتضح من الجدول السابق ما يلى: - إثـارة معامل الانحدار موجبة للمتغير المستقل، فإن ذلك ئل يعنى أن العلاقة بين المتغير

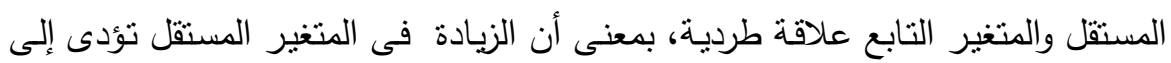

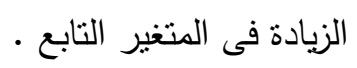
- إن زيادة المتغير المستقل بمقدار وحدة واحدة يؤدى ذلك إلى تغير طردى فى مستوي المتغير التابع بمقدار 623. وحدة تقريباً

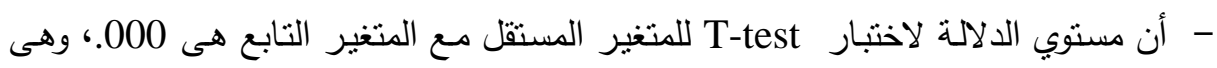
أقل من مستوي معنويـة 1\% وهذا يدعم صحة الفرض البديل بوجود علاقة معنويـة ذات دلالة إحصائية فى وجودة علاقة بين العوامل المؤثرة الداخلية وتطبيق نظم الجودة البيئية - يوضح معامل التحديد النسبة المئوية للتفسيرات التى يستطيع تقسيرها المتغير المستقل للتغيرات التى تطرأ على المتغير التابع، حيث يستطيع المتغير المستقل(العوامل المؤثرة

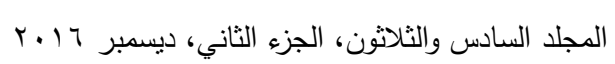


الداخلية) تفسير التغيرات التي تحدث في المتغير التابع (تطبيق نظم الجودة البيئية) بنسبة

ويالتالي يمكن صياغة نموذج الاتحدار البسيط للمتغير المستقل كما يلى:

المتغير المستقل (س) العوامل المؤثرة الداخلية

$$
\text { ص= ص= أ+ ب سا }
$$

جدول(V): قياس الارتباط بين المتغير التابع والمستقل بيان علاقة الاتحدار بين المتغير

\begin{tabular}{|c|c|c|c|c|c|}
\hline $\begin{array}{c}\text { معامل التحديد } \\
\left(\mathbf{R}^{2}\right)\end{array}$ & الاحصائية & $\begin{array}{c}\text { P- } \\
\text { value }\end{array}$ & قيم اختبار & المقَّرة & المعالم \\
\hline \multirow{2}{*}{463} & بدالة & 2.000 & 17.031 & 23.467 & الجزء الثابت \\
\hline & دالة & .000 & 17.159 & 1.109 & العوامل المؤثرة الخارجية \\
\hline \multicolumn{6}{|c|}{ قيمة اختبار (ف) = 397.456 } \\
\hline
\end{tabular}
المستقل مع المتغير التابع على حده.

يتضح من الجدول السابق ما يلى:

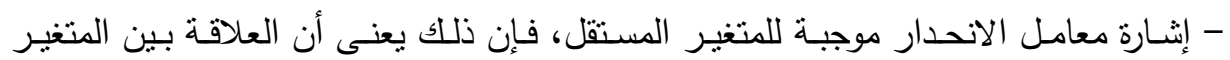

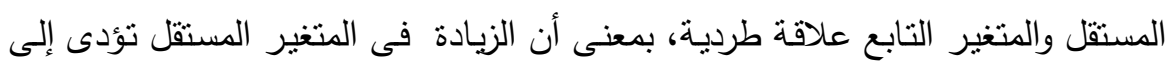

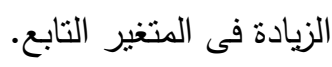

- إن زيادة المتغير المستقل بمقدار وحدة واحدة يؤدى إلى تغير طردى فى مسنوي المتغير

$$
\text { التابع بمقدار } 1.109 \text { وحدة تقريباً. }
$$

- أن مستوي الدلالة لاختبار T-test للمتغير المستقل مع المتغير التابع هى بـ 000.، وهى أقل من مستوي معنوية 1\% وهذا يدعم صحة الفرض البديل بوجود علاقة معنوية ذات دلالة

إحصائية فى وجود علاقة بين العوامل المؤثرة الخارجية وتطبيق نظم الجودة البيئية - يوضح معامل التحديد R النسبة المئوية للتقسيرات التى يستطيع تقسيرها المتغير المستقل للتغيرات التى تطرأ على المتغير التابع، حيث يستطيع المتغير المستقل(العوامل المؤثرة الخارجية) تفسير التغيرات التي تحدث في المتغير التابع (تطبيق نظم الجودة البيئية) بنسبة $46.3 \%$ 
وبالتالي يمكن صياغة نموذج الانحدار البسيط للمتغير المستقل كما يلى:

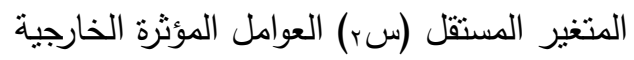

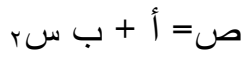
ص= (23.467) + משr

الفرض الثالث ينص الفرض الثالث على: "لاتوجد علاقة معنوية ذات دلالة إحصائية بين تطبيق نظم الجودة البيئية في الجامعات المصرية وتحسين مستوي جودة الخدمة التعليمية

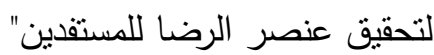

أولا: قياس مدى قوة العلاقة بين المتغير التابع والمتغير المستقل (قياس معامل الارتباط): يمكن حساب معاملات الارتباط بين (تطبيق نظم الجودة البيئية) (كمتغير مسنقل) وبين

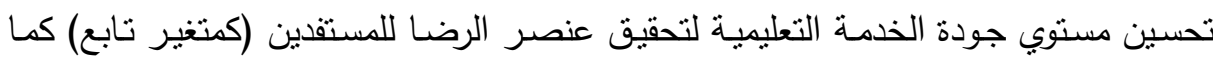

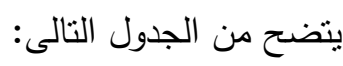
جدول(^): قياس الارتباط بين المتغير التابع والمستقل

\begin{tabular}{|c|c|c|}
\hline المعنوية & معامل الارتباط & المتغير المستقل \\
\hline .000 & $.531^{* *}$ & تطبيق نظم الجودة البيئية \\
\hline
\end{tabular}

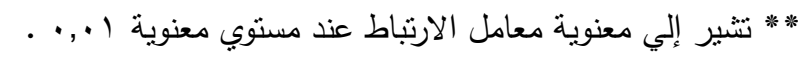

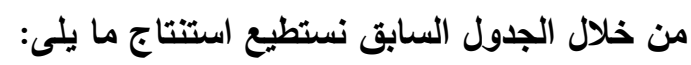

- وجود علاقة ارتباط بين عبارات المتغير المستقل (تطبيق نظم الجودة البيئية) وعبارات المتغير التابع (تحسين مسنوي جودة الخدمة التعليمية لتحقيق عنصر الرضـا للمستفدين)

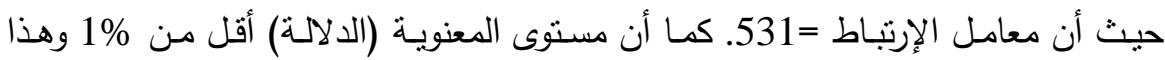
أيضاً بدل على وجود علاقة ارتباط بين المتغير التابع والمتغير المستقل. - وجود علاقة ارتباط طردية (إيجابية) بين عبارات المتغير المستقل (تطبيق نظم الجودة البيئية) وعبارات المتغير التابع (تحسين مستوي جودة الخدمة التعليمية لتحقيق عنصر الرضا للمستفدين) حيث أن إثارة معامل الارتباط موجبة، وهذا يعنى وجود علاقة إيجابية، 
فكلما كان هناك اهتمام بتطبيق نظم الجودة البيئية أدي ذلك إلي تحسين مستوي جودة الخدمة التعليمية لتحقيق عنصر الرضا للمستفدين

ثانيا: قياس أثر كل متغير مستقل على المتغير التابع على حده ( الانحدار البسيط )

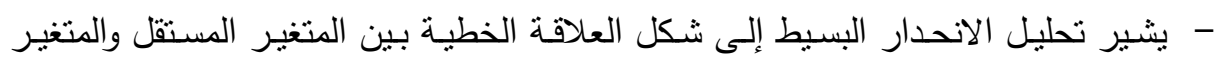

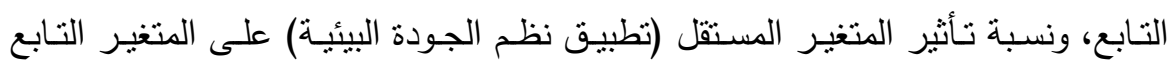
(تحسين مستوي جودة الخدمة التعليمية لتحقيق عنصر الرضا للمستفدين)، ويساعد برنامج

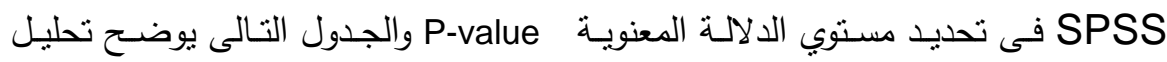
الانحدار البسيط بين المتغيرالمستقل والمتغير التابع. جدول(9): بيان علاقة الانحدار بين المتغير المستقل مع المتغير التابع على حده.

\begin{tabular}{|c|c|c|c|c|c|}
\hline معامل التحديا & الاحصائية & $\begin{array}{c}\text { P- } \\
\text { value }\end{array}$ & قيم اتتبار & المقيمة & 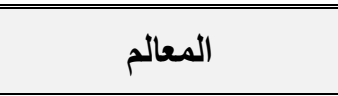 \\
\hline \multirow{2}{*}{.282} & غبر دالة & .170 & 1.375 & 4.161 & الجزء الثابت \\
\hline & | دالة & .000 & 11.590 & .744 & تطبيق نظح الجودة البيئية \\
\hline \multicolumn{6}{|c|}{ قيمة اختبار (ف) = 134.322 } \\
\hline
\end{tabular}

يتضح من الجدول السابق ما يلى:

- إثـارة معامل الانحدار موجبـة للمتغير المستقل، فإن ذلك بعنى أنس أن العلاقة بين المتغير

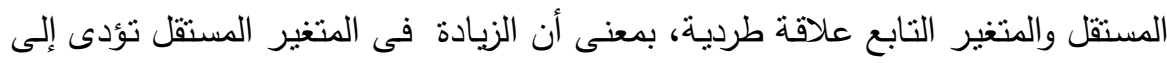

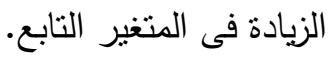
- إن زيادة المتغير المستقل بمقدار وحدة واحدة يؤدى ذللك إلى تغير طردى فى مستوي المتغير التابع بمقدار 744. وحدة تقريباً.

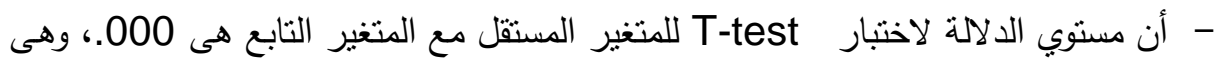
أقل من مستوي معنوية 1\% وهذا يدعم صحة الفرض البديل بوجود علاقة معنوية ذات دلالة إحصائية فى وجودة علاقة بين نطبيق نظم الجودة البيئية وتحسين مستوي جودة الخدمة التعليمية لتحقيق عنصر الرضا للمستفدين 
- يوضح معامل التحديد R النسبة المئوية للتفسيرات التى يستطيع تفسيرها المتغير المستقل للتغيرات التى تطرأ على المتغير التابع، حيث يستطيع المتغير المستقل (تطبيق نظم الجودة البيئية) تفسير التغيرات التي تحدث في المتغير التابع (تحسين مستوي جودة الخدمة التعليمية لتحقيق عنصر الرضا للمستفدين) بنسبة 28.2\%

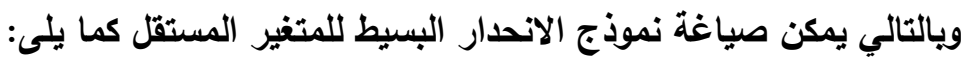
المتغير المستقل (س) نطبيق نظم الجودة البيئية ص= أ+ب ب س س أس

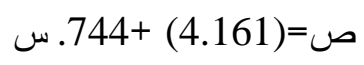
وهذا يعني صحة الفرض البديل الذي ينص على ما يلى: "توجد علاقة معنوية ذات دلالة إحصائية نطبيق نظم الجودة البيئية في الجامعات المصرية وتحسين مستوي جودة الخدمة

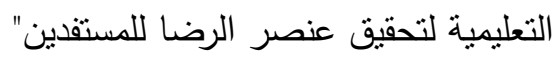
الفرض الرابع ينص الفرض الرابع على: "لاتوجد علاقة معنويـة ذات دلالة إحصائية بين

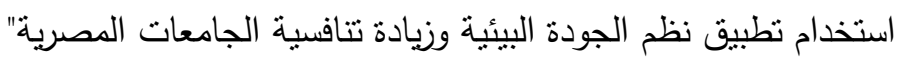
وقد حولت المتغيرات إلى قيم كمية عن طريق ربط كل عبارة من العبارات الواردة بقائمة لهـة

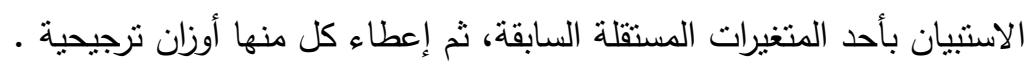
أولا: قياس مدى قوة العلاقة بين المتغير التابع والمتغير المستقل (قياس معامل الارتباط):

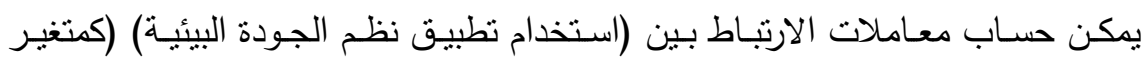
مستقل) وبين زيادة تنافسية الجامعات المصرية (كمتغير تابع) كما يتضح من الجدول التالى: جدول( • (1): قياس الارتباط بين المتغير التابع والمستقل.

\begin{tabular}{|c|c|c|}
\hline المعنويـة & معامل الارتباط & المتغير المستقل \\
\hline 2.000 & $.785^{\cdots \cdots}$ & استخدام تطبيق نظم الجودة البيئية \\
\hline
\end{tabular}

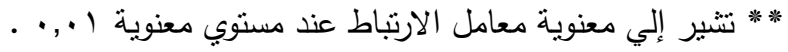

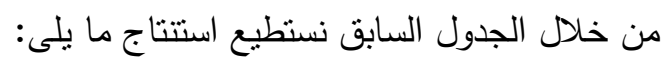
- وجود علاقة ارتباط بين عبارات المتغير المستقل (استخدام نطبيق نظم الجودة البيئية)

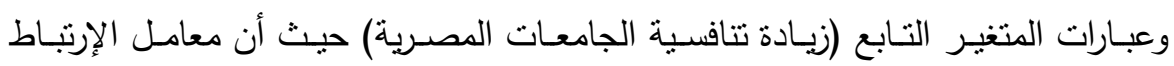

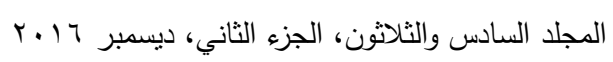




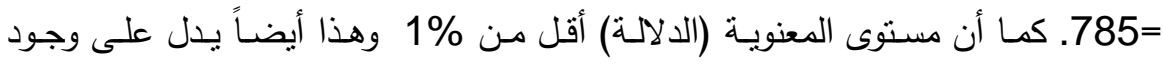

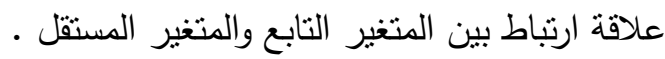
- وجود علاقة ارتباط طردية (إيجابية) بين عبارات المتغير المستقل (استخدام تطبيق نظم

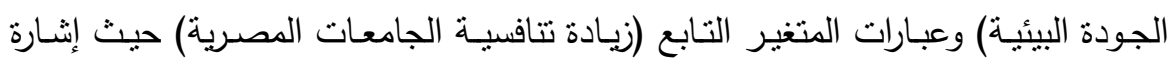
معامل الارتباط موجبة، وهذا يعنى وجود علاقة إيجابية، فكلما كان هناك اهتمام باستخدام تطبيق نظم الجودة البيئية أدي ذلك إلي زيادة نتافسية الجامعات المصرية.

ثانيا: قياس أثر كل متغير مستقل على المتغير التابع على حده ( الاتحدار البسيط ) - يشير تحليل الانحدار البسيط إلى شكل العلاقة الخطية بين المتغير المستقل والمتغير

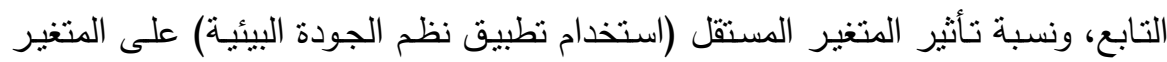

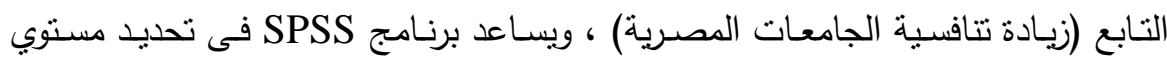

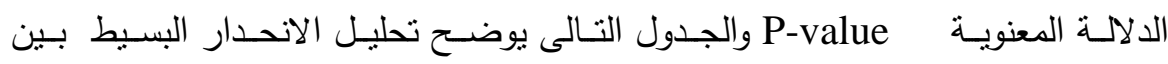
المتغيرالمستقل والمتغير التابع. جدول(11): بيان علاقة الانحدار بين المتغير المستقل مع المتغير التابع على حده

\begin{tabular}{|c|c|c|c|c|c|}
\hline معامل التحديا & الاحصائية & $\begin{array}{c}P \text { P- } \\
\text { value }\end{array}$ & قيم اختبار & المقرّة & المعالم \\
\hline \multirow[b]{2}{*}{.616} & دالة & .045 & $2.009-$ & $4.054-$ & الجزء الثابت \\
\hline & دالة & .000 & 23.420 & 1.003 & استخدام تطبيقية نظم البيئة \\
\hline \multicolumn{6}{|c|}{ مستوي الدلالة =.000 548.49} \\
\hline
\end{tabular}

يتضح من الجدول السابق ما يلى: - - إثـارة معامل الانحدار موجبة للمتغير المستقل ، فإن ذلك مالك يعنى أن العلاقة بين المتغير

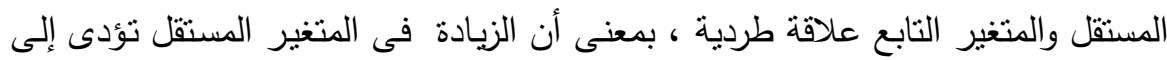

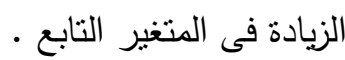
- إن زيادة المتغير المستقل بمقدار وحدة واحدة يؤدى ذللك إلى تغير طردى فى مستوي المتغير التابع بمقدار 1.003 وحدة تقريباً 
- أن مستوي الدلالة لاختبار T-test للمتغير المستقل مع المتغير التابع هى 000.، وهى مهى أقل من مستوي معنوية 1\% وهذا يدعم صحة الفرض البديل بوجود علاقة معنوية ذات دلالة إحصائية فى وجودة علاقة بين استخدام تطبيق نظم الجودة البيئية وزيادة تتافسية

$$
\text { الجامعات المصرية }
$$

- النسبة المئوية للتفسيرات التى يستطيع تفسيرها المتغير المستقل معامل التحديد للتغيرات التى تطرأ على المتغير التابع، حيث بينطيع المتغير المستقل(استخدام تطبيق نظم الجودة البيئية) تفسير التغيرات التي تحدث في المتغير التابع (زيادة تنافسية الجامعات

$$
\text { 61.6\% المصرية) بنسبة }
$$

ويالتالي يمكن صياغة نموذج الانحدار البسيط للمتغير المستقل كما يلى: المتغير المستقل (س) استخدام تطبيق نظم الجودة البيئية

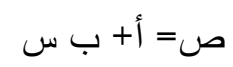

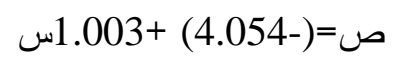

وهذا يعني صحة الفرض البديل الذي ينص "توجد علاقة معنوية ذات دلالة إحصائية بين

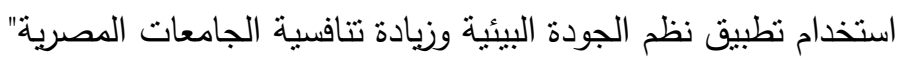

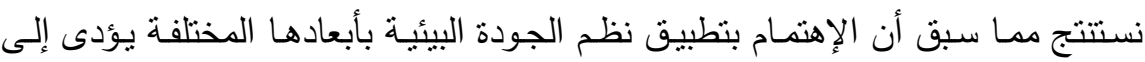
زيادة القدرة التنافسية للجامعات المصرية.

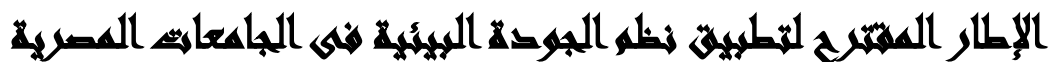

بناء على نتائج الدراسة الميدانية والتحليلات الإحصائية للعلاقات بين متغيرات البحث لإختيار الفروض، فإنه ينم تحديد المحاور الرئيسية للإطار المقترح لتطبيق نظم الجودة البيئية

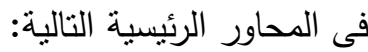
المحور الأول: الإمكانيات والقدرات (الموارد). المحور الثانى: عمليات وأنثطة نظم الجودة البيئية (العمليات). المحور الثالث: التميز والتنافسية للجامعة (المخرجات).

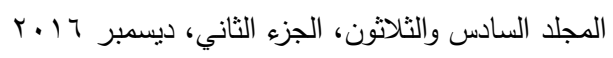


وتمثل المحاور السابقة أساس عملية منظومة الجودة البيئية، والتى يتم تطبيقها من

خلال تكامل المجهودات بين الأطراف المتمة بتحسين القدرة التنافسية للجامعات المصرية، والمتنتلة فى إدارة الجامعة والكليات ومؤسسات الدولة، بهدف وجود خريج ذو كفاءة وجودة لهون عالية وقدرة تتافسية ووعى بيئى عميق يلبى إحتياجات سوق العمل. ويتتاول الإطار المقترح كيفية تحليل تدفقات الموارد سواء البشرية أو المادية، المستحدثه لئه فى الكلية أو الجامعة تطبيق نظم الجودة البيئية بما يتلائم مع المعايير والإشتراطات البئيية الدولية المعتمدة من نظم الهيئة القومية للجودة للتعليم العالى والاعتماد، بهدف التحسين المستمر فى مجال الجودة البيئية للجامعة. ويمكن توضيح الإطار المقترح فى شكل منظومة متوازنة لنظم الجودة البيئية بالشكل التالى:

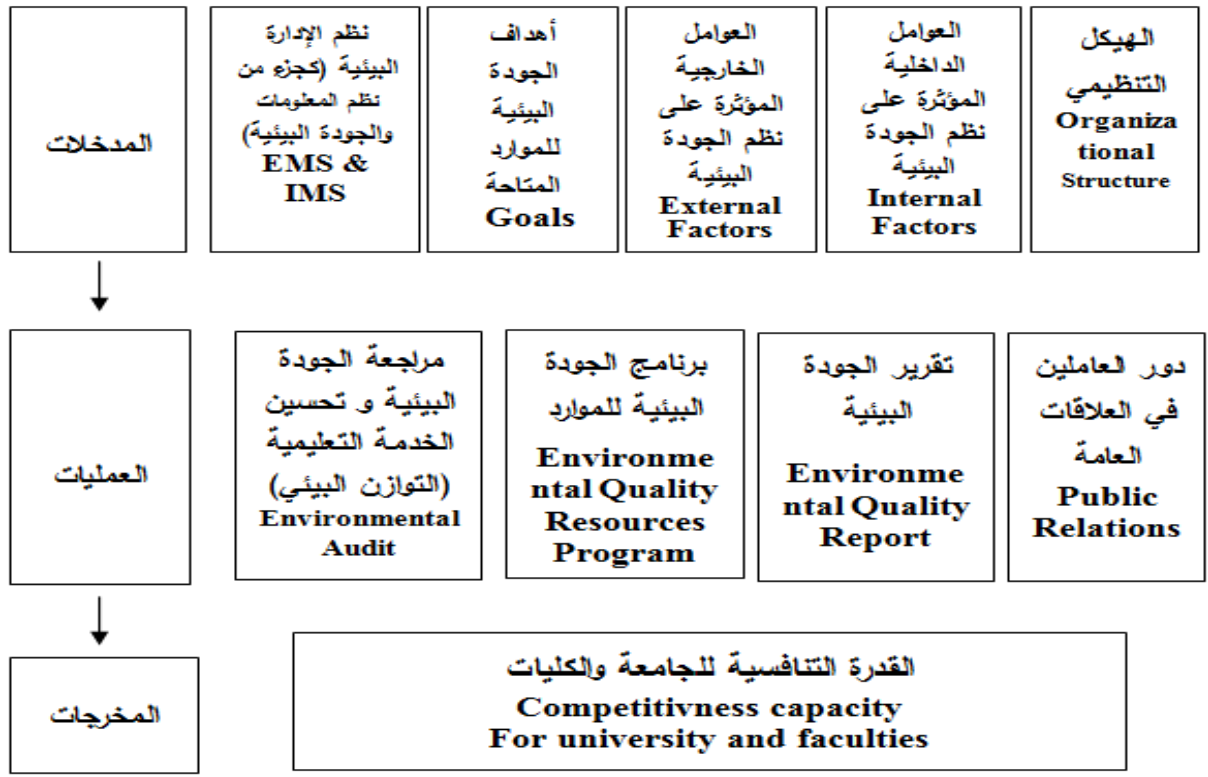

شكل رقم(1): المنظومة المتوازنة لنظم الجودة البيئية (الإطار المقترح) 
مقومات تطبيق الإطار المقترح: بعد عرض عناصر الإطار المقترح لتطبيق نظم الجودة البيئية فى الجامعات المصرية بهدف رفع قدرتها التتافسية فى سوق التعليم العالى المحلى والأقليمى والعالمى، نرى الباحثة أهمية تحديد مقومات تطبيق الإطار المقترح، والتى تشمل

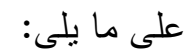
1-بناء هيكل إستراتيجى للإدارة البيئية

ب-تحليل تدفقات الموارد بالجامعة ب-مساهمة العاملين بالجامعة ع - الحاجة إلى وجود منسق لنشئون الإدارة البيئية

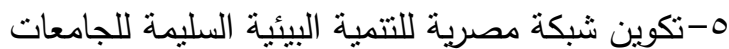

\section{تموسيامت السراسمة}

فى ضوء النتائج التى توصلت إليها الدارة، يقترح التوصيات التالية:

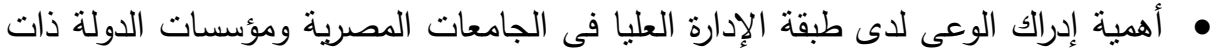
الصلة بتطبيق نظم الجودة البيئية بعناصرها الأساسية فى ظل الإطار المقترح للاراسة، نظراً للاور الحيوى الذى تلعبه فى المحافظة على الموارد المتاحة وأهميتها، والارتقاء بجودة

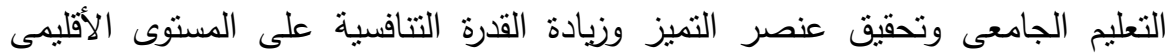
والدولى.

• توفير الدعم الكافى لإدارات الكليات، بما يضمن تحقيق الممارسات الجيدة لأنشطة وأعمال نظم الجودة البيئية، بهذف رفع مستويات المدخلات والعمليات والمخرجات التعليمية للوصول إلى مستوى من الجودة البيئية فى مجال التعليم العالى يحاكى المستوى العالمى. • من الأهية تكثيف البحوث والدراسات الأكاديمية والتطبيقية حول المداخل والأساليب الحديثة فى تطبيق نظم الجودة البيئية فى المؤسسات الخدمية وزيادة الوعى البيئى، بما

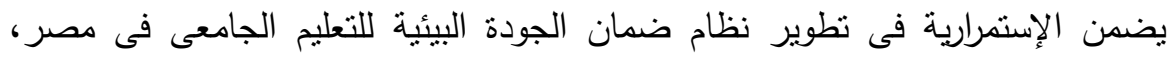


علاوة على الوعى بمنطلبات والمهارات المطلوبة لسوق العمل، وكذلك تتمية المسئولية الاجتماعية والبيئية للجامعة.

• تعميق ثقافة الجودة البيئية لدى المسئولين عن التعليم الجامعى فى مصر، وكذلك لدى الدى

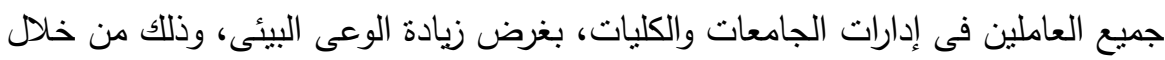

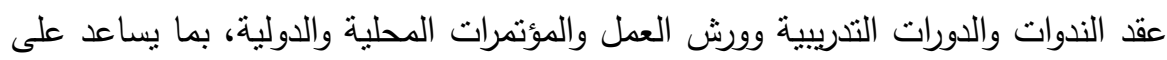
توافر وعى بيئى لدى جميع المسئولين والعاملين فى كافة المستويات الإدارية والمساعدة فى حل المشاكل البيئية، الأمر الذى يؤدى إلى دمج البعد البيئى فى نسيج الكليات ومن ثم

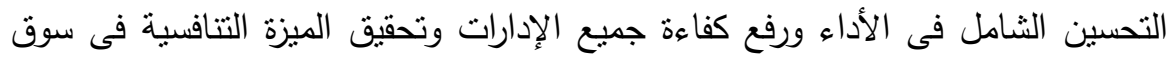
العمل.

هن الضرورى تحسين الخدمات التعليمية الجامعية بِأعنبارها المحور الرئيسى فى رفع مستوى الجودة وتطبيق نظم الجودة البيئية وتحقيق التميز فى الأداء وتحقيق عنصر الرضا بـاعيه لاى المستفدين وأصحاب المصالح بالخدمات الفعلية، الأمر الذى يؤدى إلى إلى تحسين الصورة الذهنية عن الأنشطة ومستوى الخريج الجامعى، ومن ثم يجب على المسئولين

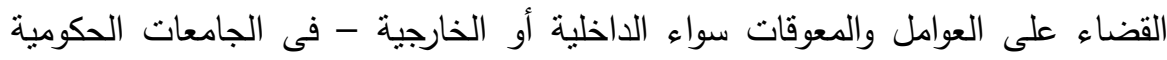
والخاصة - والتى تقف حائلا أمام تحسين مستوى الخدمات التعليمية وتطبيق نظم الجودة البيئية. الاستمرار فى نظوير نظام ضمان الجودة البيئة للتعليم الجامعى، من خلال تحديد

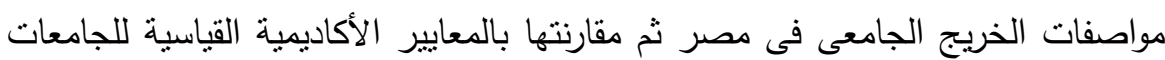
العالمية الحاصلة على شهادات الجودة العالمية، ومن ثم يجب تركيز الإنتباه للمسئولين -

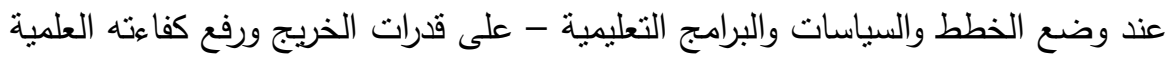
والعملية، وأيضا الوعى بمنطلبات ومهارات سوق العمل فى الداخل والخارج. 


\section{zall}

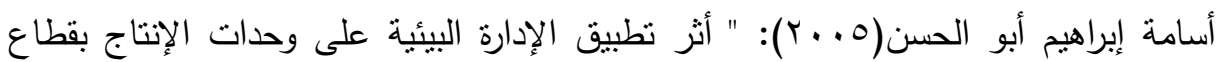

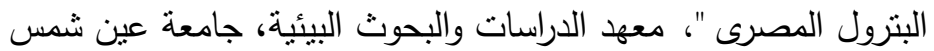

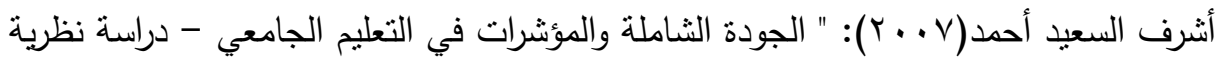

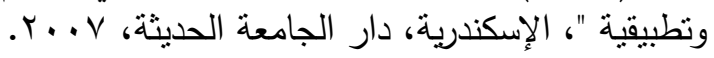

لطيفة عبد العاطى حسن إسماعيل(ب . . ب): " نظام مقترح لتطبيق نظام إدارة الجودة البيئية

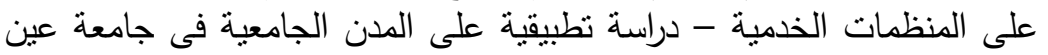

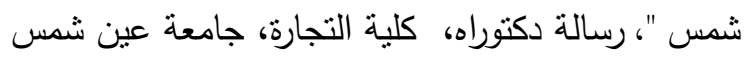

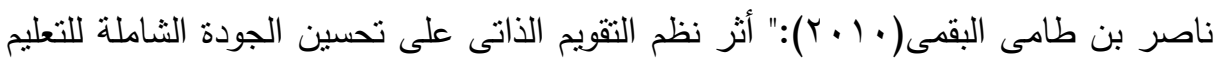
العالى "، بحث تكميلى لمعادلة درجة الماجستير، كلية التجارة، جامعة عين الفين شمس

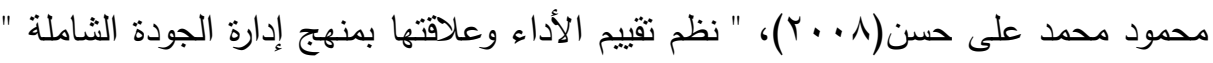

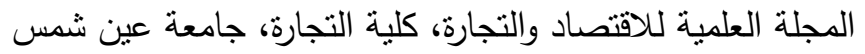

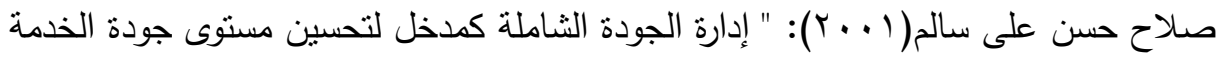
التعليمية فى الجامعات المصرية الحكومية - إطار مقترح "، رسالة دكتوراه، كلية

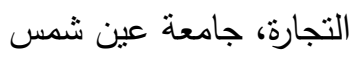

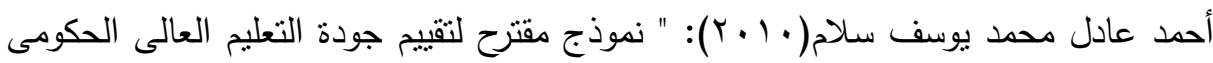
بصر "، رسالة ماجستير، جامعة عين شمس، كلية التجارة

ضياء الدين زاهر (0 ـ †): " إدارة النظم التعليمية للجودة الثاملة "، دار السحاب للنشر.

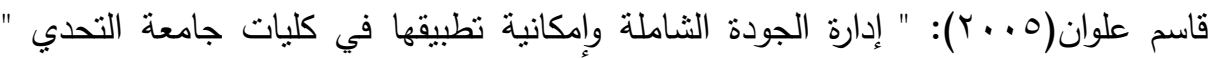

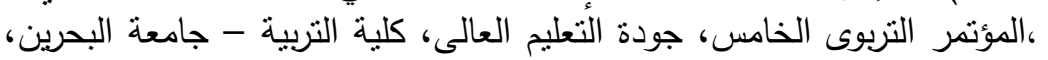

$$
\text { إبريل 1) }
$$

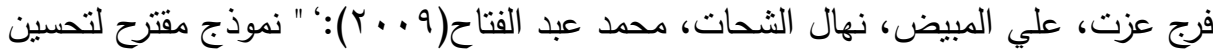

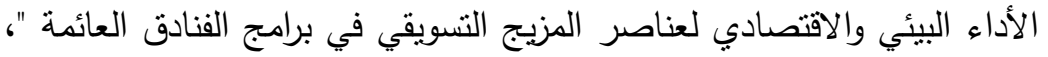

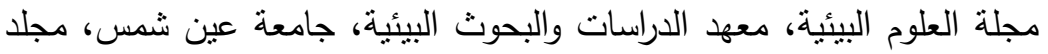

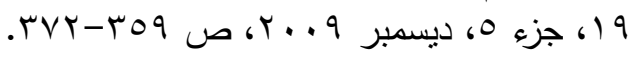

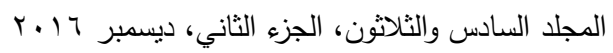




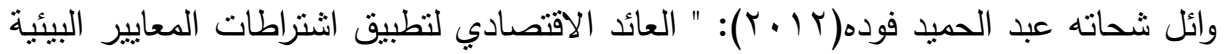

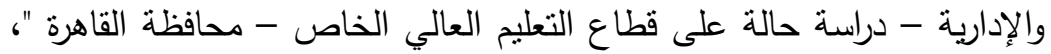

المجلة العربية لضمان جودة التعليم الجامعي، جامعة العيمة العلوم والتكنولوجيا، مجلد . • ع 0

محمد درويش، عبادة سرحان، أحمد بيومي(9 . . ب): " تقييم نظم المعلومات البيئية وآثارها

على كفاءة الأداء - دراسة مقارنة بين المؤسسات الصحفية القوانية القومية"، مجلة

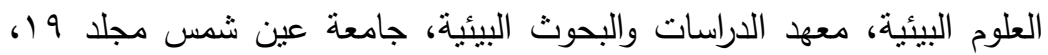

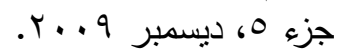

Beatriz, Janquera; Del Brío, J. Ángel, Fernández, Esteban (2012): "Clients' involvement in environmental issues and organizational performance in businesses: an empirical analysis" , Journal of Cleaner Production, vol, 37 .

Feigenbaum, A. V., (1991): “Total Quality Control”, (1st ed. in 1951) New York, Mc-Graw-Hill.

Mijanovic, K., Kopac, J., (2005): "Environmental Management System inside production", Journal of Materials Processing Technology.

Marmouche, Lamia, (2009): "Incentives and obstacles to the implementation of Environmental" , Management System (EMS) in the Egyptian industrial companies", American University Of London.

Nikolaou, I.E. a, K.I.Evangelinos (2010): "A SWOT analysis of environmental management practices in Greek Mining and Mineral", University of Aegean, Dept. of Environmental, Mitilini 81100,Greece. 


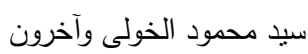

\title{
A PROPOSED FRAMEWORK FOR THE USE OF ENVIRONMENTAL MANAGEMENT SYSTEMS FOR THE IMPROVEMENT OF THE COMPETITIVENESS SERVICE ORGANIZATIONS IN EGYPT STUDY ON EGYPTIAN UNIVERSITIES
}

El Khouly, S. M. ${ }^{(1)}$; Gohar, K. M. ${ }^{(1)}$ and Marmouche, Lamia. R. ${ }^{(2)}$ 1) Faculty of Commerce, Ain Shams University 2) Faculty of Applied Languages (Department of Business and International Commerce), French University in Egypt

\begin{abstract}
The aim of this research is to propose a framework for the use of the environmental quality systems as a path for the increase of the egyptian universitites' competitivness, this is undertaken through a description and a study of the a number of internal and external factors and their relation with the envoronmental management systems and the ways of improvement of the educational service in order to enhance the competitivness of the egyptian private and public universitiesm within the period of 01-01- 2014 and 31-12-2015.

The results of this research indicate the importance of applying the environmental management systems in its several parameters, within the different egyptian universities in order to reinforce their competitiveness in both local or international market. Therefore this research recommends to apply the proposed framework to preserve and develop the available resources and improve the higher educational service and hence the competitivness of the egyptian universities.

The study concludes that applying environmental quality systems in the egyptian uniersities (in both public and private sectors) contributes to the improvement of competitivness on both environmental and econmic level.
\end{abstract}

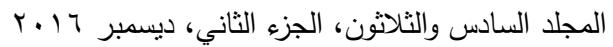

